\title{
Predicting the Ultimate Tensile Strength of AISI 1045 steel and 2017-T4 aluminum alloy joints in a laser-assisted rotary friction welding process using Machine learning: a comparison with Response surface methodology
}

\section{Germán Omar Barrionuevo}

School of Engineering, Pontificia Universidad Católica de Chile José Luis Mullo

School of Engineering, Pontificia Universidad Católica de Chile Jorge Andrés Ramos-Grez ( $\nabla$ jramos@ing.puc.cl )

School of Engineering, Pontificia Universidad Católica de Chile

\section{Research Article}

Keywords: Rotary friction welding, Steel-aluminum joining, Ultimate tensile strength, Machine learning, Response surface methodology

Posted Date: March 22nd, 2021

DOl: https://doi.org/10.21203/rs.3.rs-344995/v1

License: (c) (1) This work is licensed under a Creative Commons Attribution 4.0 International License. Read Full License 


\title{
Predicting the Ultimate Tensile Strength of AISI 1045 steel and 2017-T4 aluminum alloy joints in a laser-assisted rotary friction welding process using Machine learning: a comparison with Response surface methodology
}

\author{
Germán Omar Barrionuevo ${ }^{1}$, José Luis Mullo ${ }^{1,2}$, Jorge Andrés Ramos-Grez ${ }^{1,3}$ \\ ${ }^{1}$ Department of Mechanical and Metallurgical Engineering, School of Engineering, Pontificia Universidad \\ Católica de Chile, Av. Vicuña Mackenna, 4860, Macul, Santiago, Chile \\ ${ }^{2}$ Carrera de Tecnología Superior en Mecánica Automotriz, Instituto Superior Tecnológico Ciudad de \\ Valencia (ISTCV), Quevedo, Ecuador \\ ${ }^{3}$ Research Center for Nanotechnology and Advanced Materials (CIEN-UC), Av. Vicuña Mackenna, 4860, \\ Macul Santiago, Chile \\ E-mail address: jramos@ing.puc.cl
}

\begin{abstract}
Welding metal alloys with dissimilar melting points make conventional welding processes not feasible to be used. Friction welding, on the other hand, has proven to be a promising technology. However, obtaining the welded joint's mechanical properties with characteristics similar to the base materials remains a challenge. In the development of this work, several of the machine learning (ML) regressors (e.g., Gaussian process, decision tree, random forest, gradient boosting, and multi-layer perceptron) were evaluated for the prediction of the ultimate tensile strength (UTS) in joints of AISI 1045 steel and 2017-T4 aluminum alloy produced by rotary friction welding with laser assistance. A mixed design of experiments was employed to assess the effect of the rotation speed, friction pressure, and laser power over the UTS. Furthermore, the response surface methodology (RSM) was employed to determine an empirical equation for predicting the UTS, and contours maps determine the main interactions. A total of 48 specimens were employed to train the regressors; the 5-fold cross-validation methodology was used to find the algorithm with greater precision. The gradient boosting regressor (GBR) and Gaussian processes regressors present the highest precision with a less than $3 \%$ percentage error for the laser-assisted rotary friction welding process. The capability of the GBR exceeds the accuracy of the RSM with a coefficient of determination $\left(\mathrm{R}^{2}\right)$ of 90.90 versus $83.24 \%$, respectively.
\end{abstract}

Keywords: Rotary friction welding, Steel-aluminum joining, Ultimate tensile strength, Machine learning, Response surface methodology.

\section{Introduction}

Metal joining processes are an essential need for various industries. Proper selection of materials and procedures and safety and quality standards are important aspects in the manufacturing industry [1]. For the union of materials with different characteristics, conventional fusion welding is not feasible due to the difference between their melting points; besides, intermetallic compounds with brittle characteristics are generated [2]. Solid-state welding is a novel joining process in which two workpieces are joined under pressure, generating frictional heat, but at temperatures below the base materials' melting point [3]. Friction welding $(\mathrm{FW})$ is a solid-state joining method that produces the coalescence of materials under a compression force when workpieces rotate or move in contact with each other, producing heat and plastically displacing the material creating a welding interface [4]. Filler metal, flux, and a shielding gas are not required in this process. Due to its versatility, FW has promising industrial applicability as a mass production process for joining metals [5].

Manufacturing processes in the transport and aeronautical industry require welded cylindrical elements with good mechanical properties, low specific weight, and good corrosion resistance [6]. Joining steels and other materials in fusion welding processes can have unexpected phase propagation, grain boundary corrosion, or generation of delta and sigma ferrite phases at the weld interface [7]. The use of steel and aluminum parts in rotating systems and steel structures requires the development of reliable, efficient, and economic joining processes. Therefore, it is necessary to take certain precautions, such as using heat 
treatments or higher welding speeds, since, in this way, a certain homogeneity in the welding interface will be achieved [8]. Furthermore, the proper selection of the processing parameters influences the mechanical properties of the joints. F. F. Wang, Li, Li, \& Varis [9] mention that during the conventional rotational friction welding (RFW) process, the heat generation is mainly determined by the rotation speed, the friction pressure, and the friction time. Thus, the heating energy is very limited, especially for thin shaft welding. Winiczenko et al. [10] reported that the FW joints' nature is rather adhesive than diffusive for a couple of weight heavy alloy with aluminum alloy. H. Wang, G. Qin, P. Geng, and X. Ma [11] reached a joint efficiency of $88 \%$ by continuous drive friction welding at a low friction time and high upset pressure.

Yilmaz, Çöl \& Acet [12] applied a preheat of approximately $900{ }^{\circ} \mathrm{C}$ at the interface of a steel shaft joined to an aluminum alloy. They determined that the intermetallic layer's thickness depends linearly on the friction time's square root, which indicates that growth occurs by diffusion. W.-Y. Li, Yu, Li, Zhang, \& Wang [13] developed a friction heat-assisted electric arc welding process to join austenitic stainless steel (21-4N) and martensitic stainless steel (4Cr9Si2) from $4 \mathrm{~mm}$ diameter valves, achieving short welding times, otherwise very difficult to achieve using a conventional friction welding process. When analyzing the thermo-mechanically affected area (TMAZ) and the heat-affected zone (HAZ), they found that the plasticized area turned out to be more uniform than that achieved with the conventional method. For aluminum-aluminum joints, Campanelli, Casalino, Casavola, \& Moramarco [14] found that laser treatment induces higher microhardness values and lower longitudinal residual stress on the surface of the aluminum weld zone. Jabbari [15] showed that an increase in the preheating time leads to a decrease in the processing time. For joints of dissimilar materials, Kutsuna, Yamagami, Rathod, \& Ammar [16] studied the laser's effect on a joint of low carbon steel and an AA5052 aluminum alloy. They found a uniform layer of intermetallic compounds $\mathrm{FeAl}_{2}, \mathrm{FeAl}_{3}$, and $\mathrm{Fe}_{2} \mathrm{Al}_{5}$, which are reduced by increasing welding speed. Therefore, laser preheating presents many advantages; it is possible to use lower rotational speeds and friction pressures, thus reducing total welding time. Laser-assisted friction welding (LAFW) has been implemented in friction stir welding (FSW), but in RFW, it has been seldom explored. Recently, Mullo, Ramos-Grez, \& Barrionuevo [17] demonstrated that LAFW could increase the interlayer bonding thickness by a 4-fold, , accelerating the diffusion process by a $25 \%$ and thus increasing the UTS of aluminum-steel bars.

On the other hand, thanks to the increase in computational power and the development of new machine learning (ML) algorithms. ML has been employed to learn information directly from the data without relying on a predetermined model [18]. Supervised ML algorithms map a function from known input-output pairs to estimate relationships between them. Some of the commonly employed ML algorithms for regression task are artificial neural networks (ANN) or multi-layer perceptron (MLP) [19], decision tree (DTR) [20], support vector machines (SVM) [21], Gaussian process (GP), ensembled methods (EM), among others. EM combines several base estimators' predictions with a given learning algorithm to produce one optimal predictive model [22] and reduce overfitting risk [23]. Some of the commonly applied EM include bagging methods, random forests (RFR) [24], and boosting methods as AdaBoost and gradient boosting regressors. [25]. Boosting ML algorithms brings new opportunities for optimizing advanced manufacturing systems, converting weak algorithms to strong ones, and reducing bias and variance [26].

The applicability of ML in FW has been little explored, there are just a few publications about it, and most of them are concentrated in FSW [27]. Hartl, Vieltorf, Benker, \& Zaeh [28] applied GP to predict the ultimate tensile strength (UTS) in 6082-T6 joints of aluminum alloy processed by FSW. They concluded that GP could replace the tensile test for known materials by applying GP. The idea of replacing destructive testing with ML looks promising; however, experimentation will always be necessary to corroborate the predictions. One of the advantages of ML is that it is capable of predicting highly non-linear processes, and its application could optimize experimental designs to save material consumption and reduce the number of trials. Zhang \& Xu [29] compared GP, ANN, and response surface methodology (RSM) to predict the material removal rate during the electrical discharge diamond surface grinding of Inconel-718. They recommended combined approaches to reduce experimental trials. Alternatively, Winiczenko [30] applied a hybrid methodology combining RSM and genetic algorithm to optimize the FW process's UTS. He developed a quadratic equation for the UTS prediction as a function of the friction force, friction time, and upset force. The accuracy was determined by the coefficient of determination $\left(\mathrm{R}^{2}\right)$.

Therefore, this work's first objective is to evaluate different ML algorithms to determine which presents higher accuracy for predicting UTS in a laser-assisted rotary friction welding (LARFW) process. To achieve this goal, 48 joints of AISI 1045 steel and 2017-T4 aluminum alloy produced by LARFW were subjected to a uniaxial tensile test varying the rotation speed, friction pressure, and laser power during the welding process. Second, the RSM is applied to assess each study parameter's contribution, and statistical 
significance in the UTS performance is determined, and contour maps characterize the significant interactions.

\section{Materials and method}

\subsection{Laser-assisted rotary friction welding procedure}

The rotary friction welding was done on AISI 1045 steel and AA 2017-T4 rod size $15 \mathrm{~mm}$ in diameter and $180 \mathrm{~mm}$ in length. The base materials' nominal chemical compositions after GEDOS (Glow Emission Optical Discharge Spectroscopy) analysis are reported in Table 1. The mechanical properties of the base materials are presented in Table 2 .

Table 1. Chemical composition of the steel and aluminum alloys

\begin{tabular}{|l|c|c|c|c|c|c|c|c|}
\hline Material & \multicolumn{9}{|c|}{ Elements (wt\%) } \\
\hline \multirow{3}{*}{ AISI 1045 } & $\mathrm{Fe}$ & $\mathrm{C}$ & $\mathrm{Mn}$ & $\mathrm{Si}$ & $\mathrm{Cu}$ & $\mathrm{Al}$ & $\mathrm{P}$ & $\mathrm{S}$ \\
\cline { 2 - 10 } & 98.41 & 0.40 & 0.72 & 0.22 & 0.13 & 0.02 & 0.01 & 0.01 \\
\hline \multirow{3}{*}{ AA 2017 } & $\mathrm{Al}$ & $\mathrm{Cu}$ & $\mathrm{Mg}$ & $\mathrm{Mn}$ & $\mathrm{Fe}$ & $\mathrm{Zn}$ & $\mathrm{Cr}$ & $\mathrm{Si}$ \\
\cline { 2 - 9 } & 92.92 & 4.25 & 1.58 & 0.84 & 0.34 & 0.04 & 0.01 & 0.002 \\
\hline
\end{tabular}

Table 2. Mechanical properties of the steel and aluminum alloys

\begin{tabular}{|c|c|c|c|c|}
\hline Material & $\begin{array}{c}\text { Tensile strength } \\
(\mathrm{MPa})\end{array}$ & $\begin{array}{c}\text { Yield strength } \\
(\mathrm{MPa})\end{array}$ & $\begin{array}{c}\text { Elongation } \\
(\%)\end{array}$ & $\begin{array}{c}\text { Hardness } \\
(\mathrm{HV})\end{array}$ \\
\hline AISI 1045 & $617-680$ & $330-392$ & $<18$ & $260-330$ \\
\hline AA 2017 & $370-420$ & $215-260$ & $<18$ & $105-120$ \\
\hline
\end{tabular}

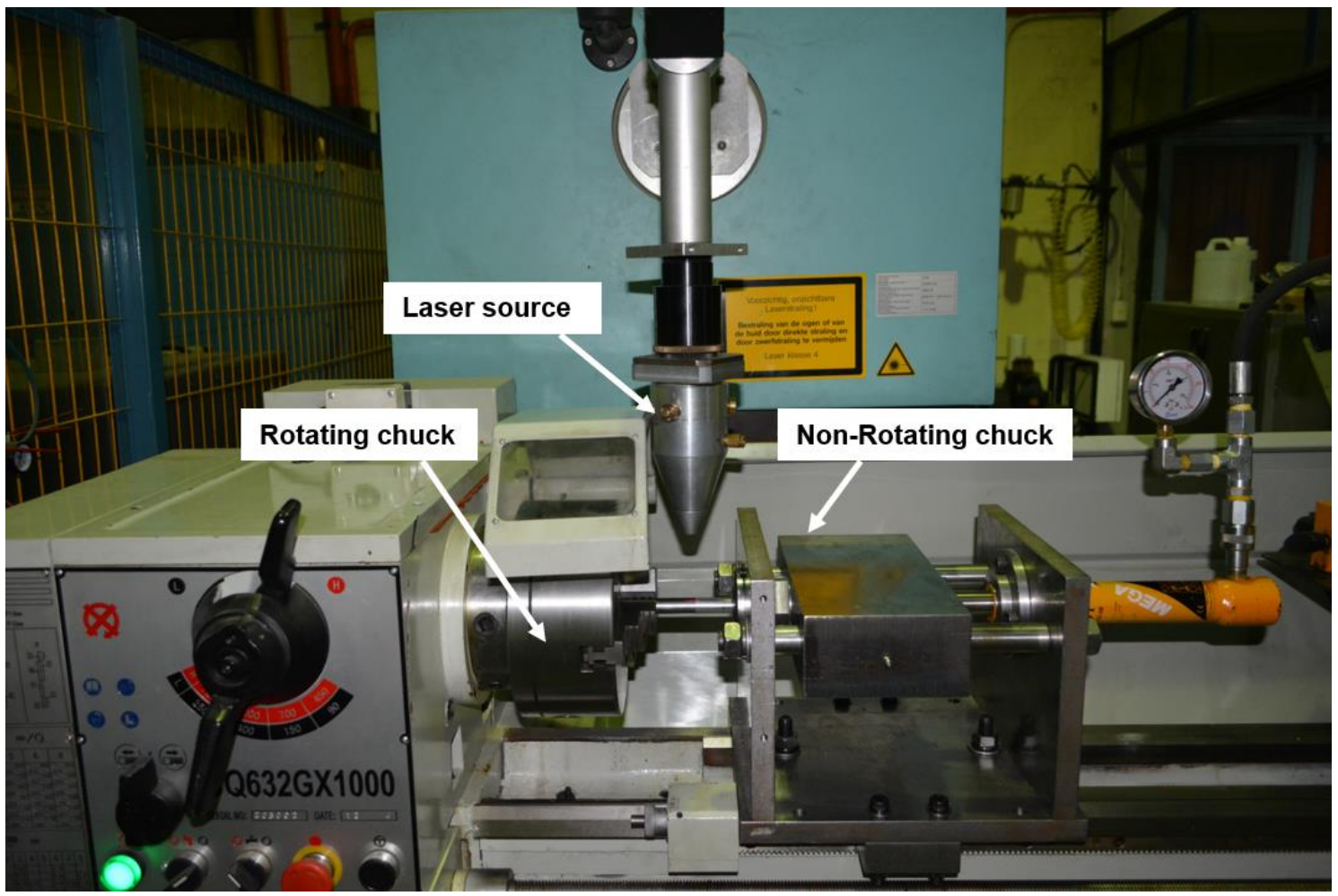

Figure 1. The experimental setup used for the laser-assisted rotary friction welding (LARFW) 
A laser-assisted rotary friction welding (LARFW) procedure was employed, where a conventional lathe machine was adapted with a $\mathrm{CO}_{2}$ laser (Oerlikon OPL3500) of $3.5 \mathrm{~kW}$, a wavelength of $10.6 \mu \mathrm{m}$, and TEM $_{00}$ (Figure 1). The lathe has 3 HP of power, 2000 RPM of rotation speed, and a distance between centers of $1000 \mathrm{~mm}$. Furthermore, a hydraulic operated pressure system has been implemented that allows friction joints to be made at two pressure levels. The pressure mechanism consists of a 5-ton capacity hydraulic cylinder, which is driven by a $300 \mathrm{cc}$ hydraulic pump. The pressure mechanism also has a pressure gauge that allows visualizing the friction and forging pressures.

The joining process consists of preheating the steel rod for 40 seconds; the friction process starts until the rotational speed $(\mathrm{N})$ is reached at $1600 / 1800 \mathrm{rpm}$, and then the axial friction pressure $(14 / 21 \mathrm{MPa})$ was applied by the hydraulic mechanism until achieving forge for 60 seconds. Finally, the forging pressure was applied (42.1 MPa) for 40 seconds. The process parameters are listed in Table 3.

The ASTM E-8 standard was applied to test the ultimate tensile strength (UTS) of the welded specimens. The tensile test was performed using a universal testing machine (Instron 3368, Zwick) with a 50-kN capacity of $0.02 \mathrm{~s}^{-1}$ strain rate.

\subsection{Design of experiments}

The rotational speed and friction pressure were evaluated at two levels due to the experimental setup's limitations. The study's parameters and levels were selected by significance in the FW process reported in the literature [6],[11],[30],[31],[32]. The laser power was controlled at four levels, from no laser-assistance $(0 \mathrm{~W})$ to 600,800 , and $1000 \mathrm{~W}$. The experiments were repeated three times for each set of parameters with a total of 48 produced specimens. The obtained results were processed statistically with Minitab $19 \AA$, where an analysis of variance (ANOVA) was conducted to analyze the main effects and their interactions to determine each factor's contribution. The main effects were defined as the mean response difference, which describes a single independent variable's action on the dependent variable (UTS).

Table 3. LARFW processing parameters and levels

\begin{tabular}{|c|c|c|c|}
\hline ID & N (rpm) & FP $(\mathbf{M P a})$ & LP $(\mathbf{W})$ \\
\hline S1 & 1600 & 14 & 0 \\
\hline S2 & 1600 & 21 & 0 \\
\hline S3 & 1800 & 14 & 0 \\
\hline S4 & 1800 & 21 & 0 \\
\hline S5 & 1600 & 14 & 600 \\
\hline S6 & 1600 & 14 & 800 \\
\hline S7 & 1600 & 14 & 1000 \\
\hline S8 & 1600 & 21 & 600 \\
\hline S9 & 1600 & 21 & 800 \\
\hline S10 & 1600 & 21 & 1000 \\
\hline S11 & 1800 & 14 & 600 \\
\hline S12 & 1800 & 14 & 800 \\
\hline S13 & 1800 & 14 & 1000 \\
\hline S14 & 1800 & 21 & 600 \\
\hline S15 & 1800 & 21 & 800 \\
\hline S16 & 1800 & 21 & 1000 \\
\hline
\end{tabular}

2.1 Machine learning algorithms

Several of the most popular algorithms were used in this study. Decision tree, random forest, gradient boosting, Gaussian process, and multi-layer perceptron were accurately detailed in [33]. Extreme gradient 
boosting regressor (XGBRegressor) is an optimized distributed gradient boosting library designed to be highly efficient, flexible, and portable [34]. The employed hyperparameters are described in Table 4.

Table 4. Hyperparameters selection for algorithms implementation

\begin{tabular}{|c|l|}
\hline ML Algorithm & \multicolumn{1}{c|}{ Hyperparameters } \\
\hline DTR & Maximum depth $=20$ \\
\hline RFR & $\begin{array}{l}\text { Number of trees in the forest }=2000, \\
\text { Maximum depth }=20\end{array}$ \\
\hline GBR & $\begin{array}{l}\text { Number of trees }=2000, \\
\text { Learning rate }=0.1\end{array}$ \\
\hline \multirow{3}{*}{ XGBR } & $\begin{array}{l}\text { Number of trees }=2000, \\
\text { Maximum depth }=20, \\
\text { Learning rate }=0.1\end{array}$ \\
\hline GPs & $\begin{array}{l}\text { Kernel }=\text { Radial based function }(\mathrm{RBF}), \\
\text { Noise level } \alpha=0.001, \\
\text { Number of optimizers }=9\end{array}$ \\
\hline \multirow{2}{*}{ MLP } & $\begin{array}{l}\text { Hidden layers }=4, \\
\text { Activation function }=\text { relu, } \\
\text { Number of iterations }=2000\end{array}$ \\
\hline
\end{tabular}

The computations were performed in Google Colaboratory (Colab) environment using Scikit-learn and XGBoost libraries [35][36] on a CPU, which was an Intel ${ }^{\circledR}$ Core $^{\mathrm{TM}} \mathrm{i} 7-7700 \mathrm{HQ}$ at $2.8 \mathrm{GHz}$, with $12 \mathrm{~Gb}$ of RAM installed.

\subsection{Accuracy evaluation}

A total of 48 samples were employed; the dataset was randomized and then split into training (80\%) and testing $(20 \%)$ portions. The input parameters were the rotation speed $(\mathrm{N})$, friction pressure (FP), and laser power (LP), while the target value was the UTS. Before initiating the training process, the data were scaled using zero mean and unit variance. Five-fold Cross-validation (CV) was employed to avoid overfitting during the training process [23],[37]. To assess the prediction accuracy, Barrionuevo et al. [33] introduced an index of merit (IM), which combines multiple metrics to get a unique metric of the algorithms' accuracy. As the magnitude of the index approaches zero, the lower the error is achieved. The IM is calculated in the form of Eq. (1), whose components are the coefficient of determination $\left(\mathrm{R}^{2}\right)$, the mean squared error (MSE), and the mean absolute error (MAE) determined by equations (2), (3), and (4), respectively.

$$
\begin{gathered}
I M=\sqrt{\left(1-R^{2}\right)^{2}+M S E+(M A E)^{2}} \\
R^{2}=1-\frac{\sum_{i}^{N}\left(y_{i}-\hat{y}_{i}\right)^{2}}{\sum_{i}^{N}\left(y_{i}-\bar{y}_{i}\right)^{2}} \\
M S E=\frac{1}{N} \sum_{i}^{N}\left(y_{i}-\hat{y}_{i}\right)^{2} \\
M A E=\frac{1}{N} \sum_{i}^{N}\left|y_{i}-\hat{y}_{i}\right|
\end{gathered}
$$

Once identified which algorithm presents the higher accuracy (lower IM), feature importance (FI) analysis was employed. FI assigns a score to input features based on how useful they are at predicting a target variable (UTS). Moreover, FI provides scores that help us provide obtain insight into the data, and the model can improve the efficiency and effectiveness of a predictive model on the predictions.

\section{Results and discussion}

3.1 Uniaxial tensile strength evaluation. 
During the welding process, a flux formation around the aluminum rod was observed (Figure 2). The flash formation is mainly influenced by the friction pressure, leading to more significant deformation of the aluminum side, causing a greater flash effect due to the higher mechanical pressure [38]. After the RFW process, the specimens were prepared for the tensile test. Figure 3 shows the specimens after welding after machined for tensile test and after tensile test. It is possible to observe that the failure occurred at the welding interface.

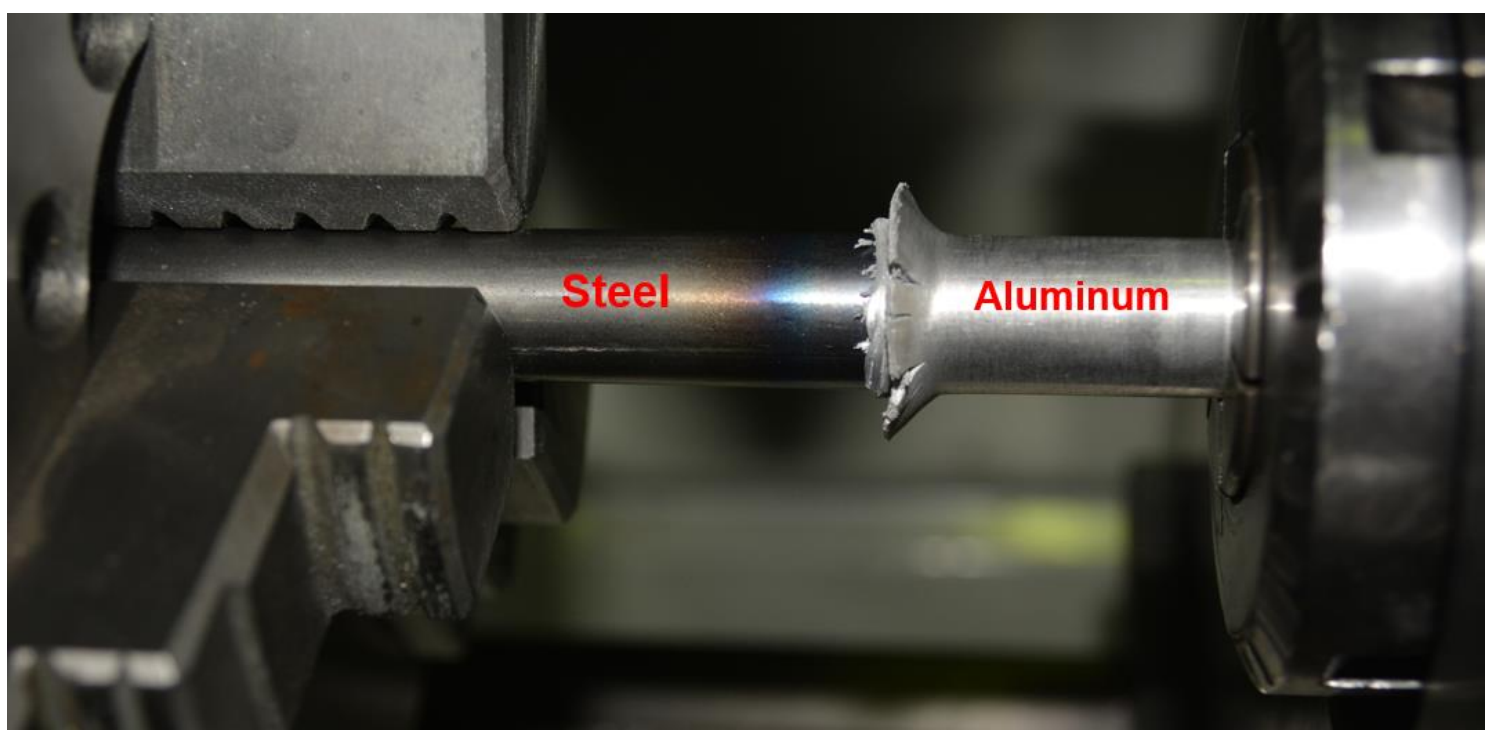

Figure 2. Flux formation around the aluminum alloy during rotary friction welding

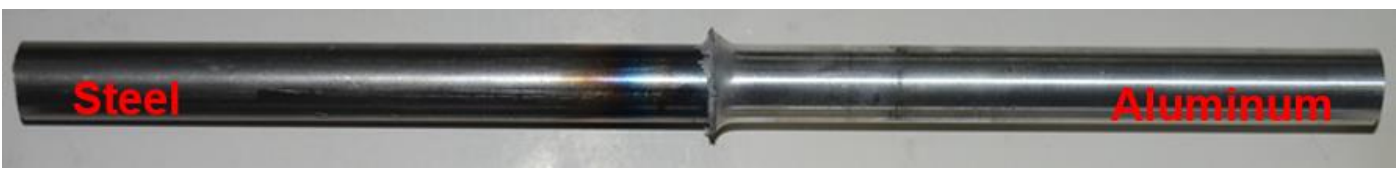

a)

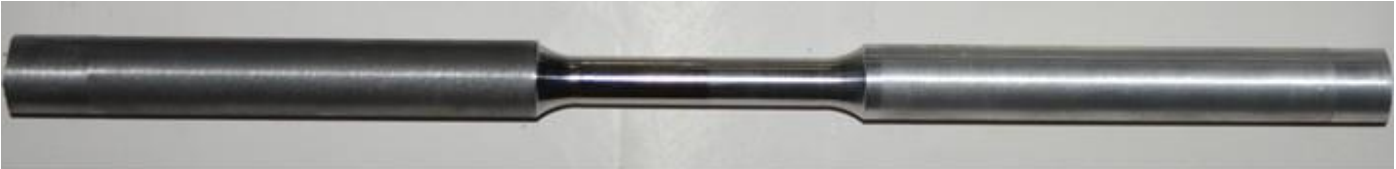

b)

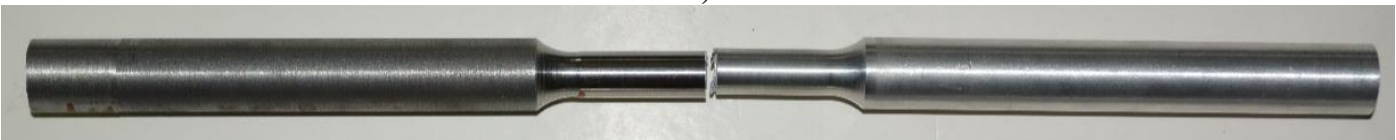

c)

Figure 3. Welded joint specimen: a) as processed, b) after machined for tensile test, c) after tensile test up to fracture

Figure 4 illustrates the range of UTS values obtained as a function of the process parameters. For the specimens manufactured by RFW without laser assistance (S1, S2, S3, and S4), the higher the friction pressure, the lower the UTS value. While for the LARFW process, the dominant parameter is laser power. The higher the laser power, the higher the UTS. For the RFW, the highest UTS value was 175.7 MPa in specimen S3. While for the LARFW, the highest UTS was 215.4 MPa. 


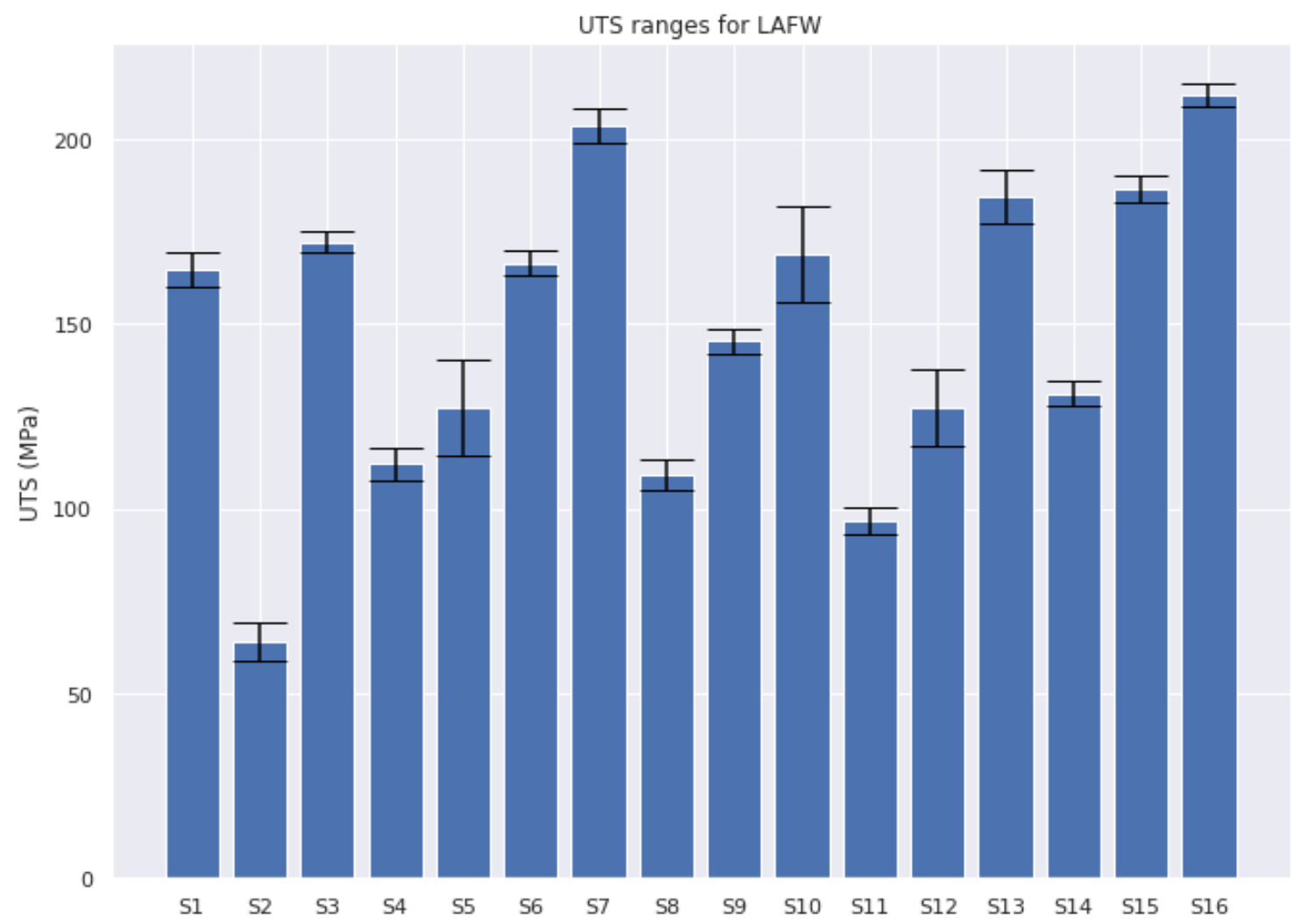

Figure 4. Boxplot of LARFW, UTS evaluation

\subsection{Statistical analysis}

Figure 5 shows a graph illustrating the main effects of the three factors. The main effects graph is used to observe how one or more factors influence a continuous response, here the UTS. For this study, the most statistical significative factor was the laser power. $\mathrm{N}$ and FP do not significantly affect the UTS value. Figure 6 summarizes the interaction effects between N, FP, and LP values for the UTS impact. The largest effect is observed for N and LP interactions, as indicated by the curve's slope. 


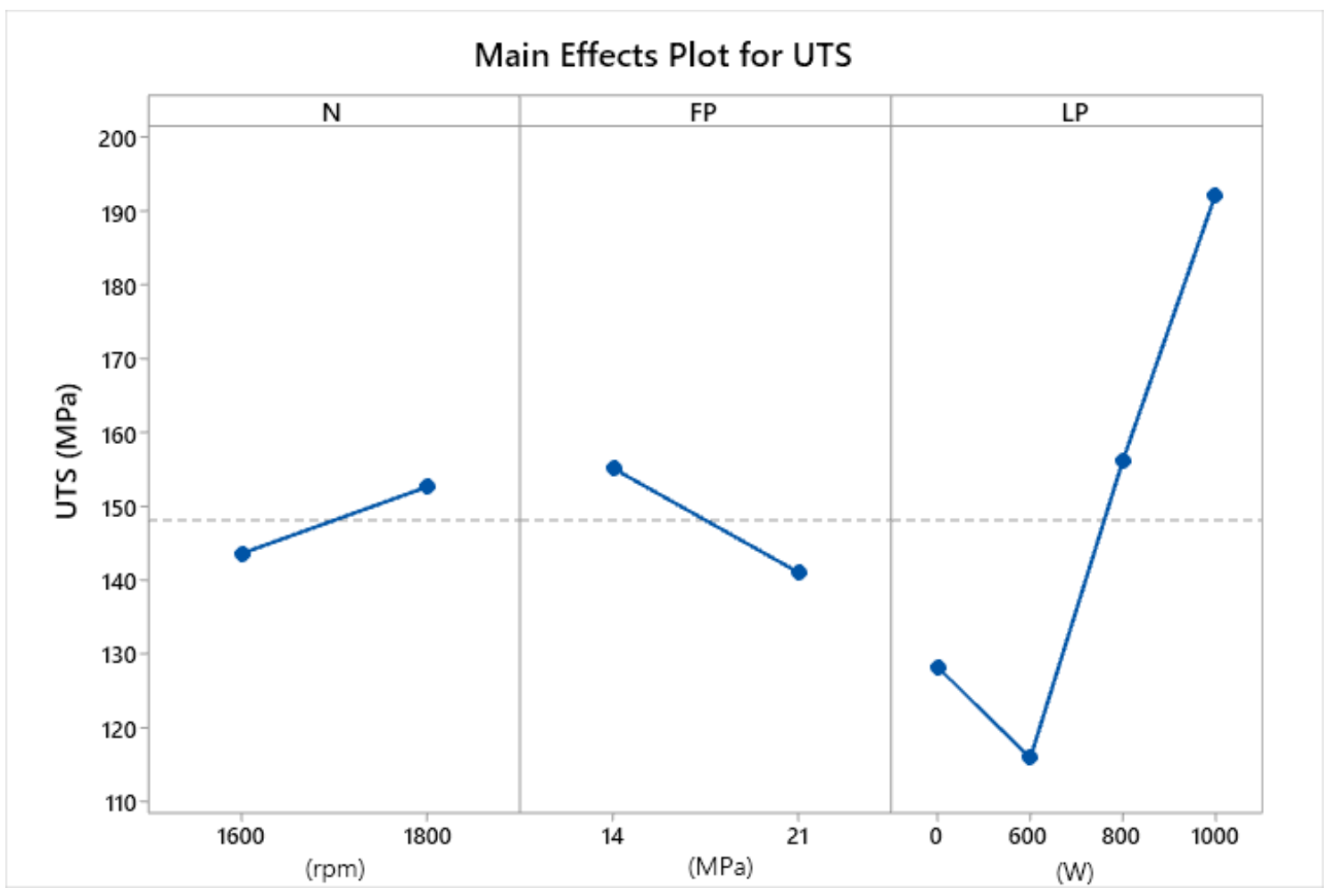

Figure 5. Main effects of experimental factors on the UTS

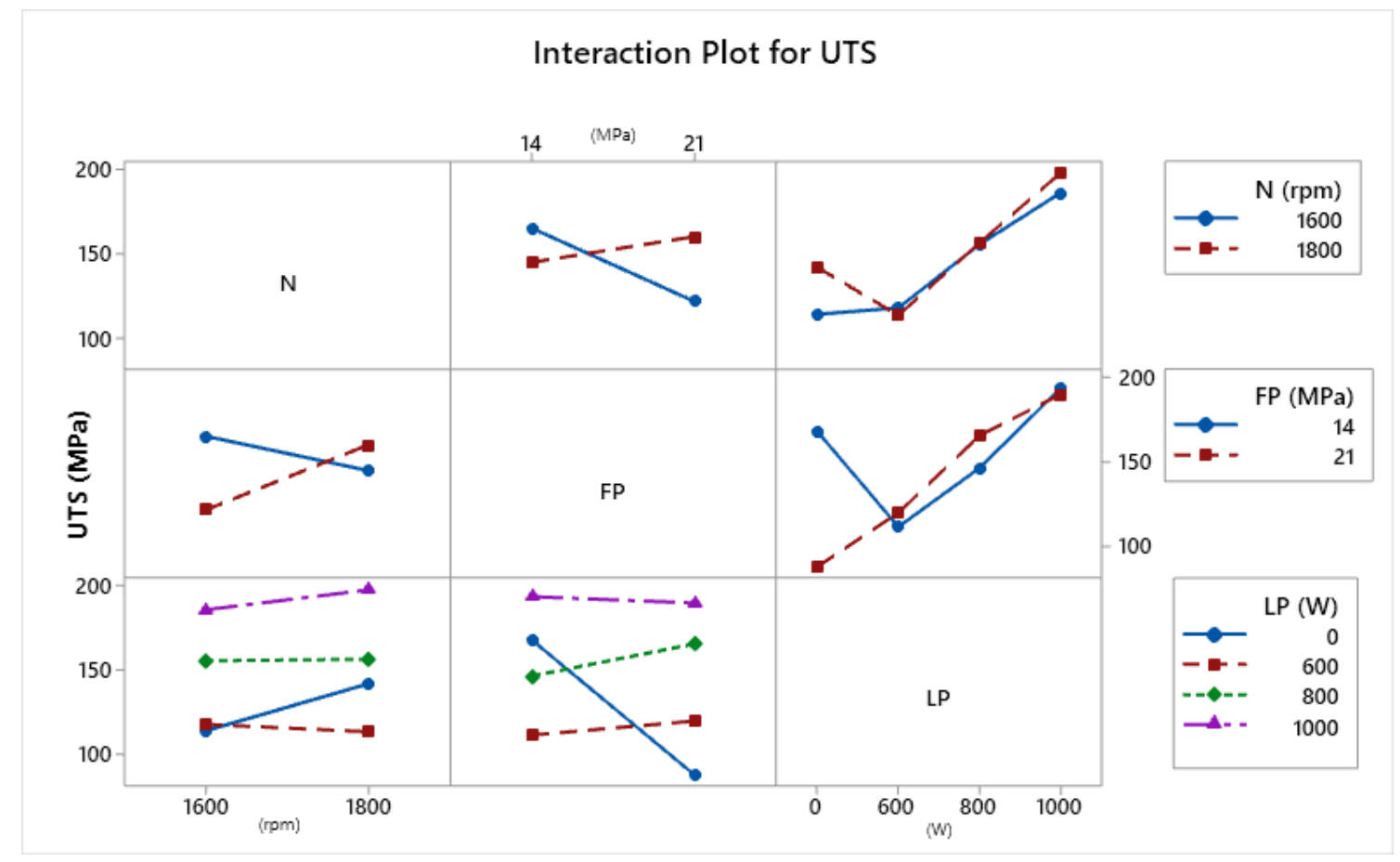

Figure 6. Interaction plot of factors on the overall UTS

The analysis of variance (ANOVA) is reported in Table 5. Each factor's significance is determined using the p-value; a p-value of less than 0.05 indicates that the factors or their interaction are statistically significant. Therefore, FP and LP and their interactions are statistically significant. Furthermore, the rotational speed does not play a significant role in LARFW, but it influences FP interaction. An empirical equation has been derived through the response surface methodology with a confidence level of $95 \%$. 
Table 5. ANOVA results for ultimate tensile strength

\begin{tabular}{|c|r|r|r|r|r|}
\hline Source & DF & Adj SS & Adj MS & F-Value & P-Value \\
\hline Model & 7 & 68614,0 & 9802,0 & 42,55 & 0,000 \\
\hline Linear & 3 & 36334,8 & 12111,6 & 52,57 & 0,000 \\
\hline $\mathrm{N}$ & 1 & 1397,3 & 1397,3 & 6,07 & 0,018 \\
\hline FP & 1 & 6009,7 & 6009,7 & 26,09 & 0,000 \\
\hline LP & 1 & 28927,7 & 28927,7 & 125,57 & 0,000 \\
\hline Square & 1 & 19609,9 & 19609,9 & 85,12 & 0,000 \\
\hline LP*LP & 1 & 19609,9 & 19609,9 & 85,12 & 0,000 \\
\hline 2-Way & 3 & 24776,1 & 8258,7 & 35,85 & 0,000 \\
Interaction & & & & & 0,000 \\
\hline N*FP & 1 & 10382,9 & 10382,9 & 45,07 & 0,079 \\
\hline N*LP & 1 & 747,2 & 747,2 & 3,24 & 0,000 \\
\hline FP*LP & 1 & 13646,0 & 13646,0 & 59,23 & \\
\hline Error & 40 & 9215,1 & 230,4 & & 0,000 \\
\hline Lack-of-Fit & 8 & 7167,5 & 895,9 & 14,00 & \\
\hline Pure Error & 32 & 2047,6 & 64,0 & & \\
\hline Total & 47 & 77829,1 & & & \\
\hline
\end{tabular}

Df: degrees of freedom, SS: sum of squares, MS: mean square, F, and P-value: statistics.

$$
\begin{gathered}
U T S=1364-0.627 N-81.2 F P-0.178 L P+0.04202 N \times F P-0.000105 N \times L P+ \\
0.01288 F P \times L P+0.000199 L P^{2}
\end{gathered}
$$

The goodness of the model given by the Eq. (5) is reported in Table 6. The coefficient of determination reaches a value superior to $83 \%$ for the predicted UTS. Adjusted $R^{2}\left(R^{2}(\operatorname{adj})\right)$, a modified version of $R^{2}$, adds precision and reliability by considering the impact of additional independent variables that tend to skew the results of $\mathrm{R}^{2}$ measurements. $\mathrm{S}$ is measured in the UTS units representing the variation of how far the data values fall from the true response surface.

Table 6. RSM model summary

\begin{tabular}{|c|c|c|c|}
\hline $\mathbf{S}$ & $\mathbf{R}^{\mathbf{2}}$ & $\mathbf{R}^{\mathbf{2}}$ (adj) & $\mathbf{R}^{\mathbf{2}}$ (pred) \\
\hline 15,1782 & $88,16 \%$ & $86,09 \%$ & $83,24 \%$ \\
\hline
\end{tabular}

Figure 7, Figure 8, and Figure 9 show contour plots of the interaction between the welding parameters N, FP, and LP. Figure 7 shows that the highest UTS is obtained in the region where the highest laser power is combined with the highest friction pressure. In Figure 8, the interaction between speed and laser power is observed. It shows a quadratic response for the $\mathrm{N}$ as a function of LP; through the contour plot is possible to distinguish a range where the laser power achieves the lowest UTS $(200-600 \mathrm{~W})$. The interaction between rotational speed and friction pressure is depicted in the contour plot in Figure 9. In this case, the higher the speed and lower friction pressure produced the lowest UTS. While at the highest FP, and N the UTS performance was improved. 


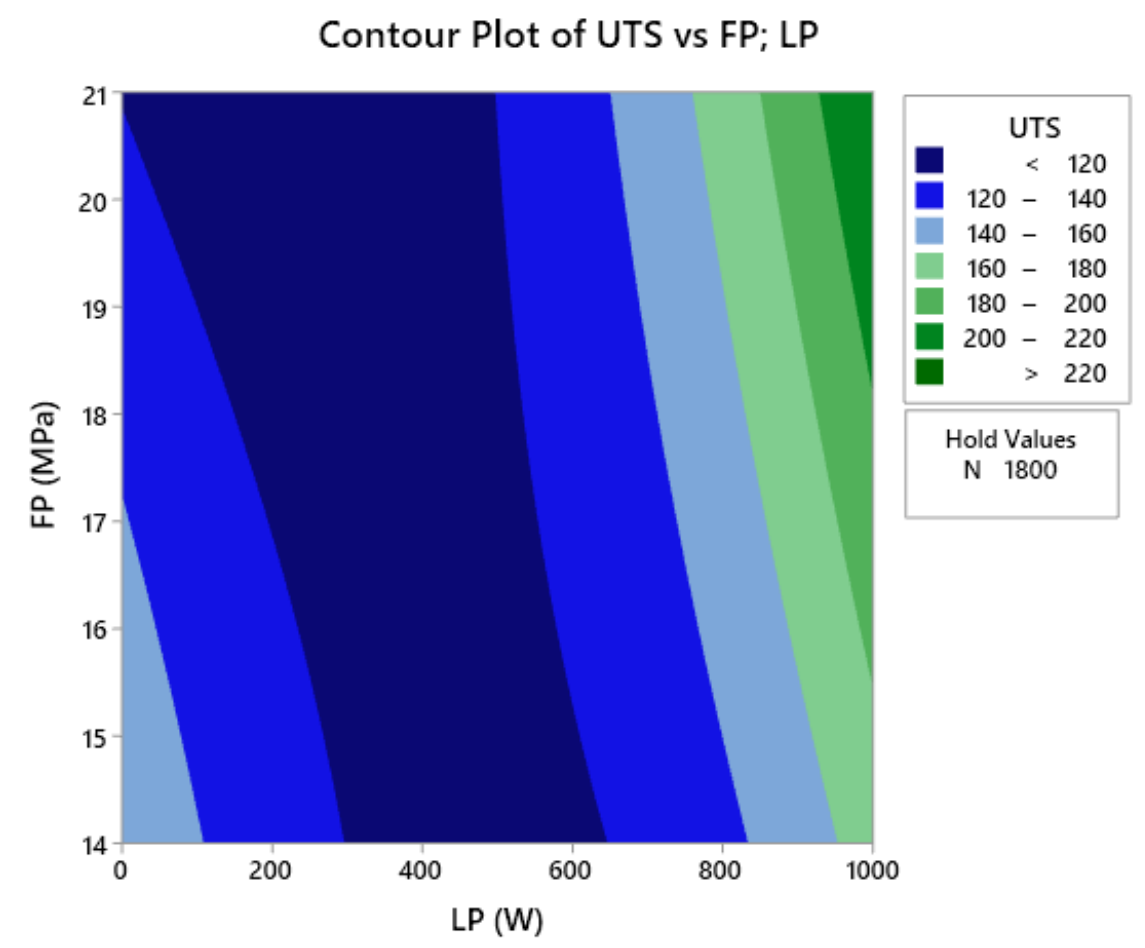

Figure 7. Contour plot of interaction between laser power and friction pressure

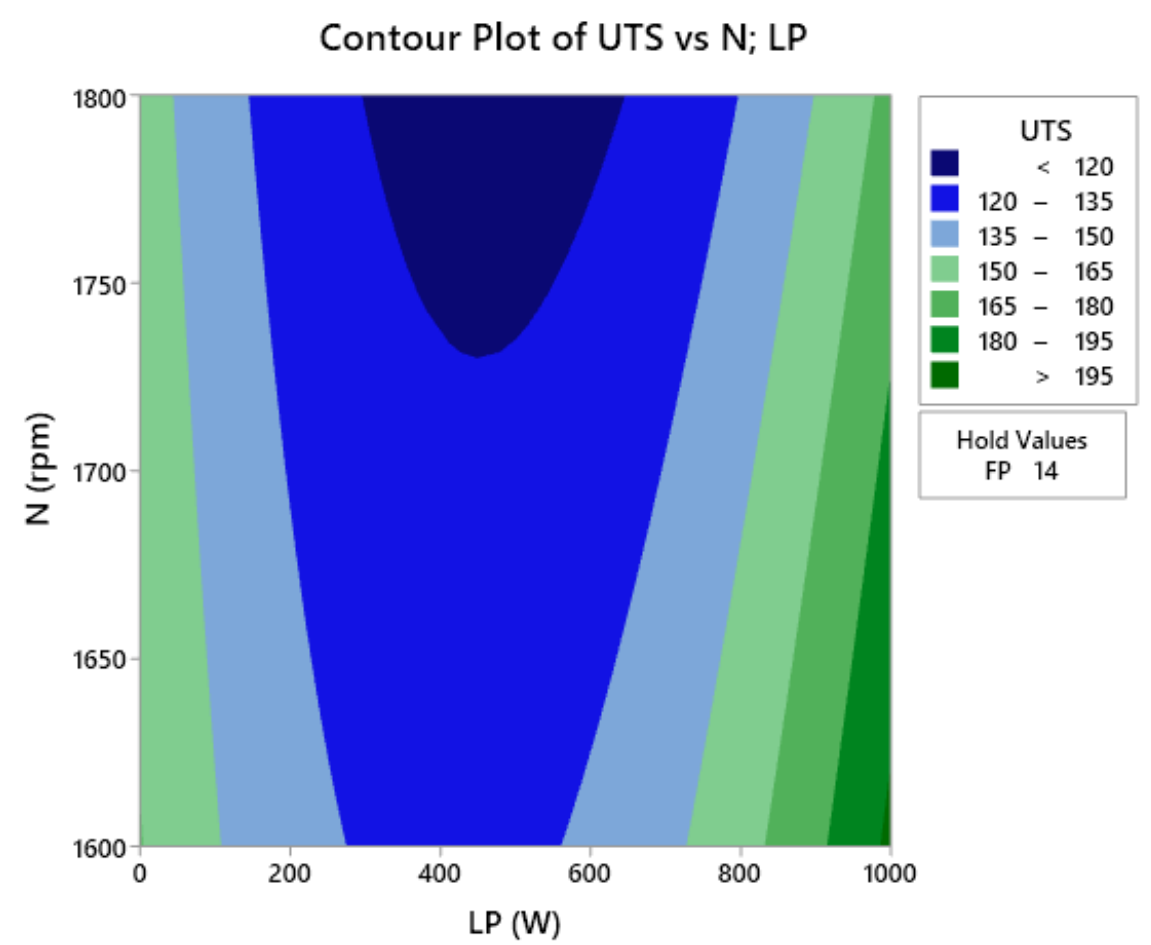

Figure 8. Contour plot of interaction between laser power and rotational speed 


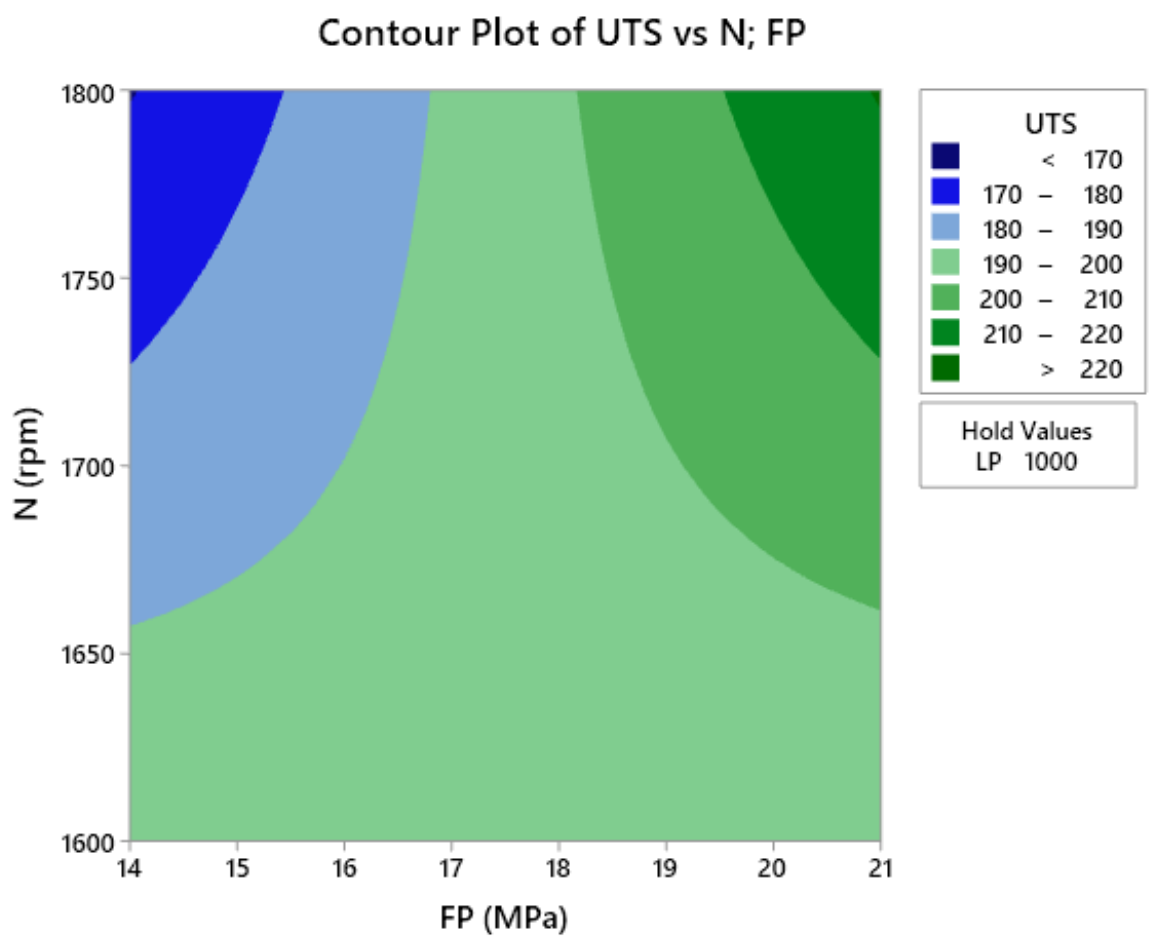

Figure 9. Contour plot of interaction between friction pressure and rotational speed

Additionally, a Pareto chart shows the standardized effect of the parameters, where the laser power contributes the most to the variability in the UTS response. The reference line on the chart indicates which effects are significant.

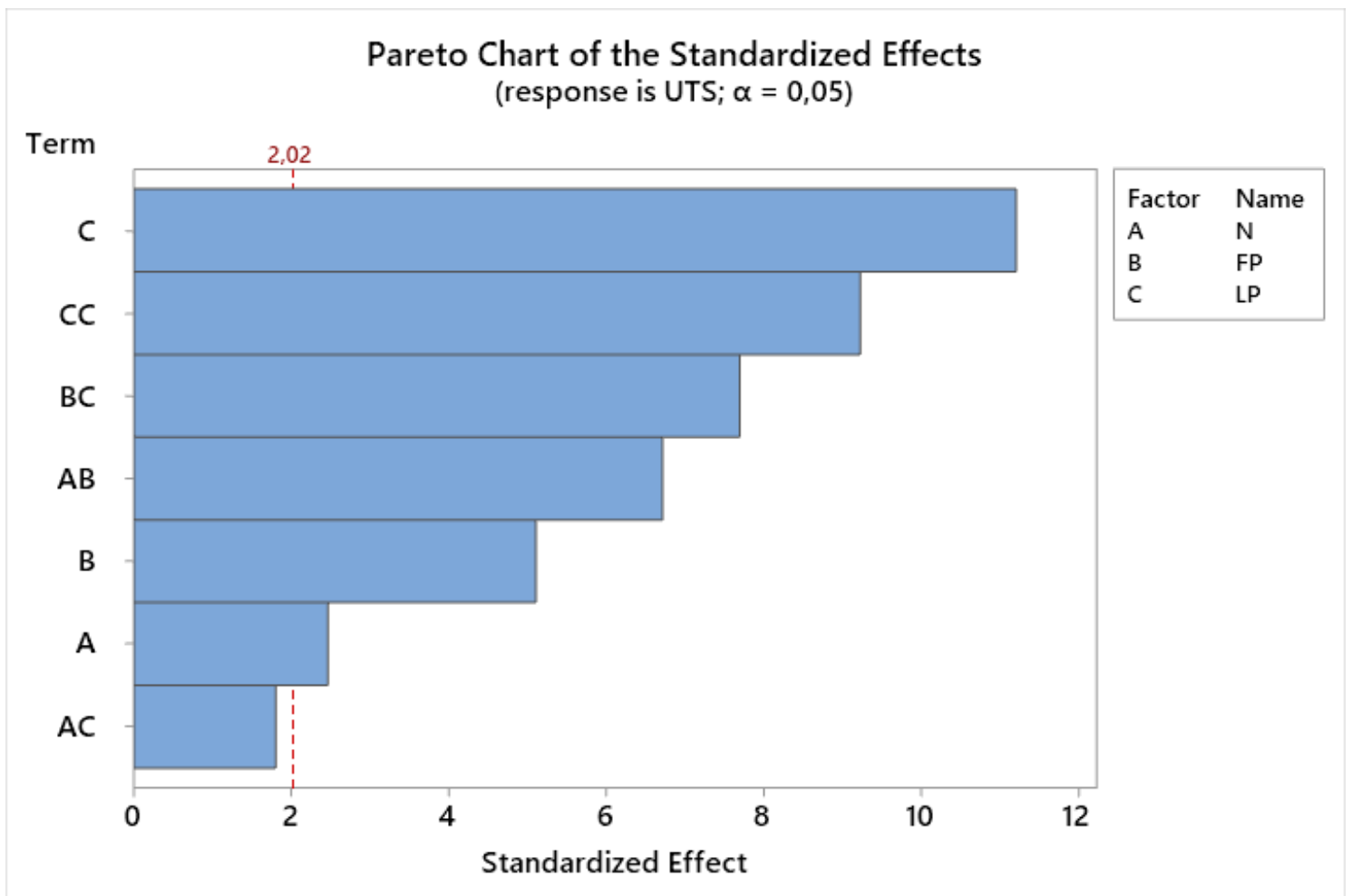

Figure 10. Pareto chart of the standardized effect 


\subsection{Machine learning evaluation}

Figure 11 illustrates the ML algorithms' behavior for predicting the UTS; the vertical axis shows the predicted value and the measured value's horizontal axis, both were scaled to zero means. In Table 7 it is reported the metrics obtained for the $\mathrm{CV}$ and testing procedures. For the CV, GBR appears the most accurate algorithm with the highest $\mathrm{R}^{2}$, the lowest RMSE, MAE, and the corresponding lowest IM. GPs also show good performance with low IM. The remaining algorithms show lower $\mathrm{R}^{2}$ than GBR and GPs and higher RMSE and MAE, with IMs higher than 0.5345 . For the testing dataset, almost every algorithm performance shows good accuracy; just the RFR shows poor accuracy, with the highest IM.

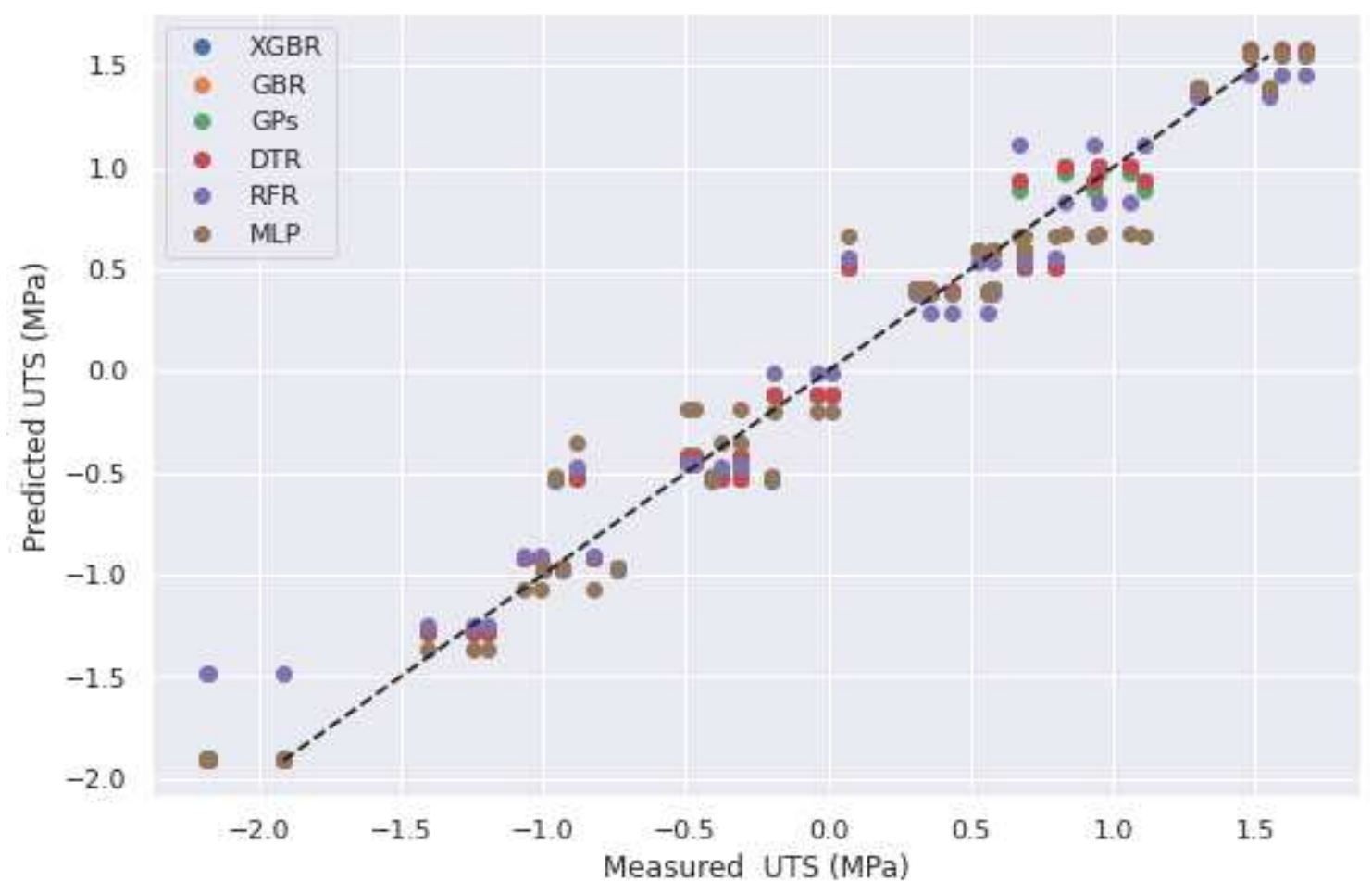

Figure 11. Scatter plot for comparing ML regressors accuracy in the UTS prediction.

Table 7. Performance of the ML algorithms employed to predict the UTS for the CV and testing dataset

\begin{tabular}{|c|c|c|c|c|c|c|c|c|}
\hline & \multicolumn{4}{|c|}{ Cross-validation } & \multicolumn{4}{c|}{ Testing } \\
\hline ML Algorithm & $\mathbf{R}^{\mathbf{2}}$ & RMSE & MAE & IM & $\mathbf{R}^{\mathbf{2}}$ & RMSE & MAE & IM \\
\hline GBR & 0.9091 & 0.0687 & 0.2049 & 0.3449 & 0.9759 & 0.1971 & 0.1825 & 0.2697 \\
\hline GPS & 0.8339 & 0.1266 & 0.2424 & 0.4615 & 0.9761 & 0.1965 & 0.1804 & 0.2679 \\
\hline MLP & 0.7986 & 0.1534 & 0.303 & 0.5345 & 0.9693 & 0.1975 & 0.1807 & 0.2694 \\
\hline DTR & 0.7731 & 0.1758 & 0.2913 & 0.5586 & 0.9760 & 0.1975 & 0.1826 & 0.2701 \\
\hline XGBR & 0.7716 & 0.1770 & 0.2917 & 0.5606 & 0.9758 & 0.1975 & 0.1831 & 0.2704 \\
\hline RFR & 0.7568 & 0.1898 & 0.3064 & 0.5855 & 0.9200 & 0.3598 & 0.2635 & 0.4531 \\
\hline
\end{tabular}

Figure 12 shows the performance during training and testing for the GBR algorithm. This observation provides insight into the algorithm's excellent performance for the UTS prediction in laser-assisted rotary friction welding. 


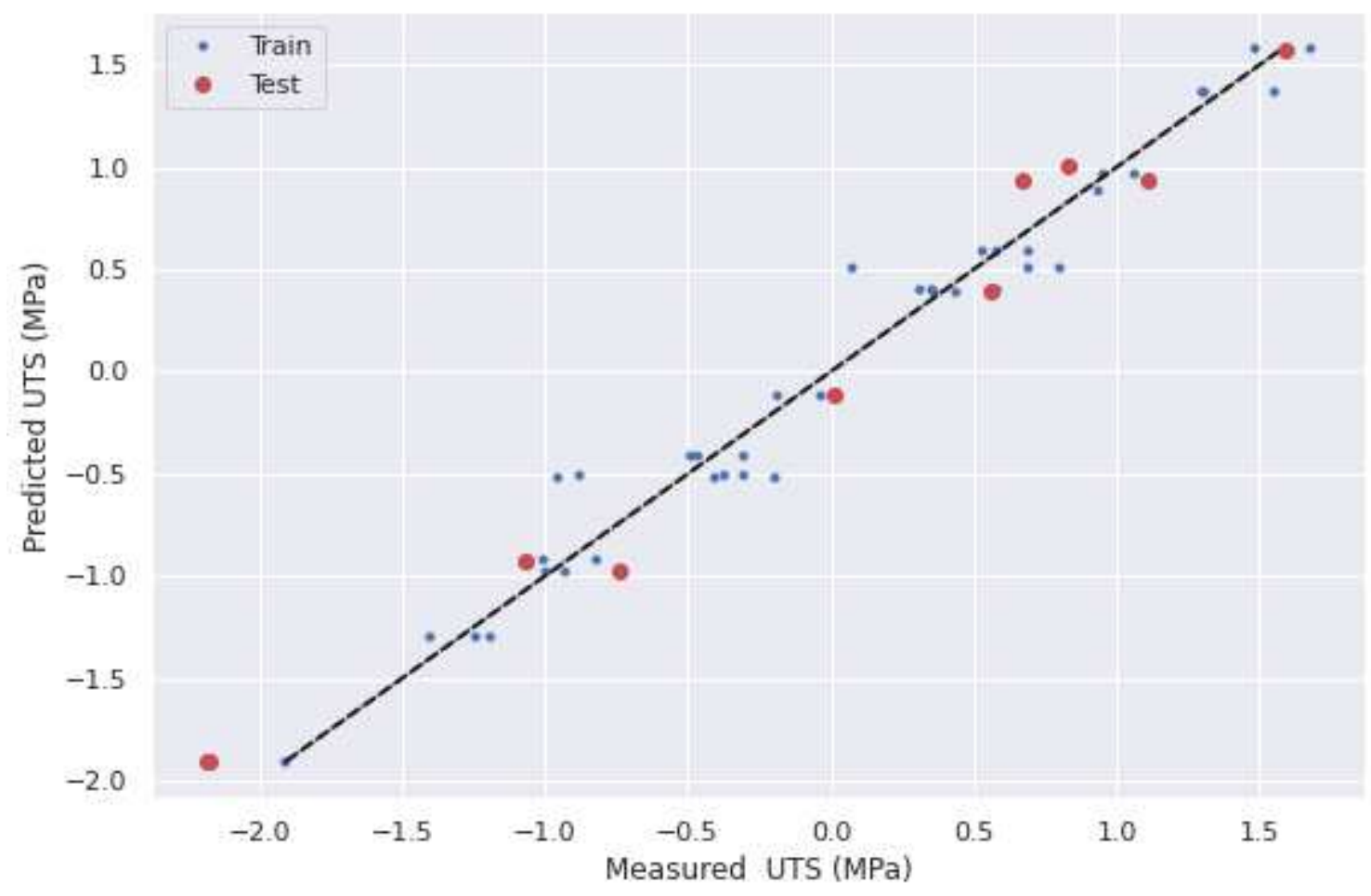

Figure 12. Scatter plot for accuracy evaluation of the GBR performance in the UTS prediction.

\subsection{Feature important analysis.}

Figure 13 shows the feature importance analysis, where the laser power represents the main factor for predicting the UTS. The rotation speed (Feature 0) represents less than $10 \%$ of the model predictivity, friction pressure (Feature 1) represents around 30\%, while laser power appears the most significant parameter, with a score superior to $60 \%$ (Feature 2).

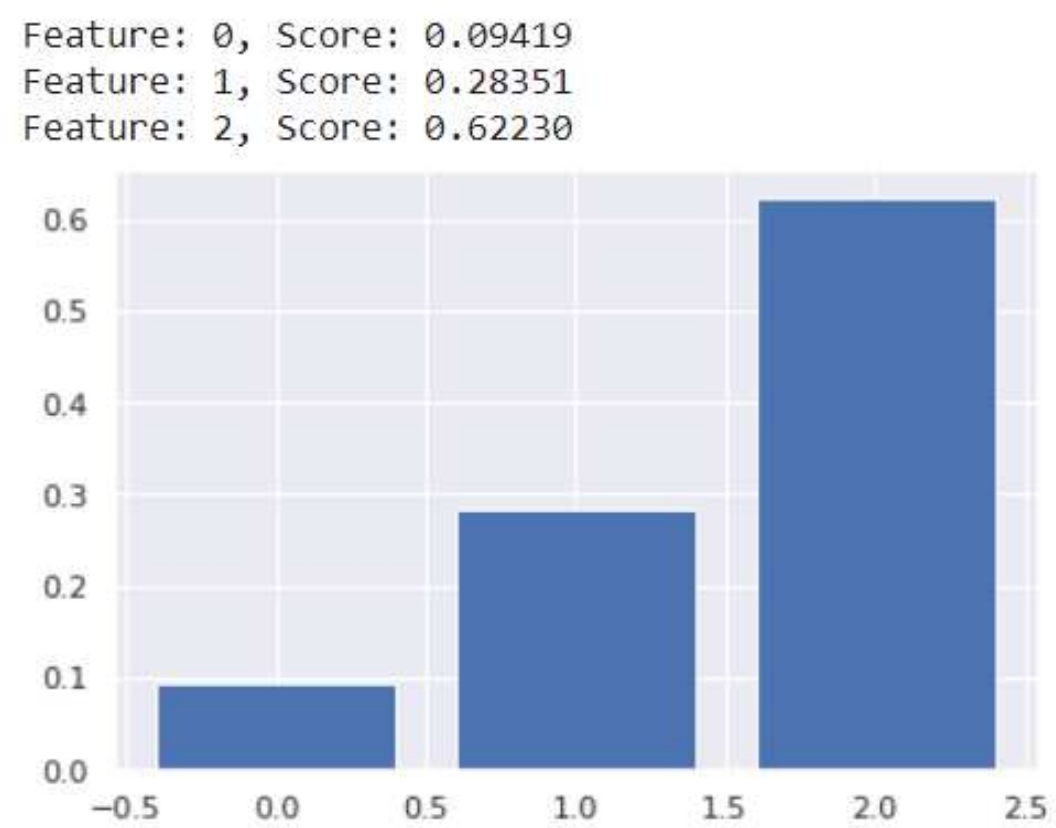

Figure 13. Feature importance analysis of the processing parameters in LARFW 
The FI results agree with the Pareto chart, corroborating that the laser power represents the most statistically significant factor for the UTS prediction in laser-assisted rotary friction welding.

\section{Conclusions}

This paper evaluates several machine learning regressors to predict the UTS, resulting from a laser-assisted rotary friction welding process between 2017-T4 aluminum and AISI 1045 steel. The following conclusions can be drawn:

1) The application of the laser improves the ultimate tensile strength. For the conventional rotary friction welding process, there is an average UTS value of $119 \mathrm{MPa}$, while for the laser-assisted process, there is a UTS value of $152 \mathrm{MPa}$, which represents an increase of near to $28 \%$. The range of values for UTS in RFW covers values from 64 to $175.7 \mathrm{MPa}$. For LAFW, there are values from 96.45 to $215.4 \mathrm{MPa}$.

2) The algorithms that better perform predicting the UTS were gradient boosting regressor and Gaussian process regressor, which show the highest coefficient of determination, the lowest root mean squared error, and the lowest mean absolute error.

3) The ML algorithms' accuracy was examined through the index of merit (IM), which appears as a robust estimator since it groups three metrics in one. The lower the IM, the more accurate the algorithm predicts the UTS.

4) The empirical Equation obtained through the response surface methodology explains $83.64 \%$ of the UTS performance variation, denoting the importance of the laser power factor on the UTS prediction. It is important to note that this empirical relationship only represents this particular LARFW set up and materials system used.

5) The GBR algorithm outperforms the prediction capability of the RSM, obtaining a coefficient of determination $\left(\mathrm{R}^{2}\right)$ higher than the RMS value.

\section{Acknowledgments}

SENESCYT has founded this study through grant number ARSEQ-BEC-000329-2017. The authors also acknowledge the Research Center for Nanotechnology and Advanced Materials (CIEN-UC) and ANID FONDECYT \#1201068 project and FONDEQUIP EQM160091 project.

Authors' contributions Germán Omar Barrionuevo: paper original idea, conceptualization, data curation, investigation, methodology, statistical analysis, writing-original draft and editing.

José Luis Mullo: literature review, design of experiments, experimental setup, and data generation, tensile testing, and manuscript proofread and valuable comments.

Jorge Andrés Ramos Grez: paper original conceptualization, close supervision and guidance during research process, index of merit formulation, critical advice, and manuscript proofread and funding.

Funding This study is financially supported by the SENESCYT grant no. ARSEQ-BEC-000329-2017 and ANID FONDECYT grant no. 1201068 project.

Data availability Source files are available in GitHub:

https://github.com/GermanOmar/LAFW/blob/master/LARFW_IJAMT.ipynb

\section{Declarations}

Ethics approval Not applicable.

Consent for publication All listed authors approve to publish.

Conflict of interest The authors have no competing interests. 


\section{References}

[1] W. Li, A. Vairis, M. Preuss, and T. Ma, "Linear and rotary friction welding review," Int. Mater. Rev., vol. 61, no. 2, pp. 71-100, 2016.

[2] K. P. Mehta, "A review on friction-based joining of dissimilar aluminum-steel joints," J. Mater. Res., vol. 34, no. 1, pp. 78-96, 2019.

[3] W. Cai et al., "A state-of-the-art review on solid-state metal joining," J. Manuf. Sci. Eng. Trans. ASME, vol. 141, no. 3, pp. 1-35, 2019.

[4] M. Maalekian, "Friction welding - Critical assessment of literature," Sci. Technol. Weld. Join., vol. 12, no. 8, pp. 738-759, 2007.

[5] G. Ananda Rao and N. Ramanaiah, "Dissimilar metals AISI 304 steel and AA 2219 aluminium alloy joining by friction welding method," Mater. Today Proc., vol. 19, pp. 902-907, 2019.

[6] G. L. Wang, J. L. Li, J. T. Xiong, W. L. Wang, P. Y. MA, and F. S. Zhang, "Study on the friction interface evolution during rotary friction welding of tube," J. Adhes. Sci. Technol., vol. 33, no. 10, pp. 1033-1046, 2019.

[7] G. S. Chander, G. M. Reddy, and A. V. Rao, "Influence of Rotational Speed on Microstructure and Mechanical Properties of Dissimilar Metal AISI 304-AISI 4140 Continuous Drive Friction Welds," J. Iron Steel Res. Int., vol. 19, no. 10, pp. 64-73, 2012.

[8] G. K. Padhy, C. S. Wu, and S. Gao, "Auxiliary energy assisted friction stir welding - Status review," Sci. Technol. Weld. Join., vol. 20, no. 8, pp. 631-649, 2015.

[9] F. F. Wang, W. Y. Li, J. L. Li, and A. Vairis, "Process parameter analysis of inertia friction welding nickel-based superalloy," Int. J. Adv. Manuf. Technol., vol. 71, no. 9-12, pp. 1909-1918, 2014.

[10] R. Winiczenko, O. Goroch, A. Krzyńska, and M. Kaczorowski, "Friction welding of tungsten heavy alloy with aluminium alloy," J. Mater. Process. Technol., vol. 246, pp. 42-55, 2017.

[11] H. Wang, G. Qin, P. Geng, and X. Ma, "Interfacial microstructures and mechanical properties of friction welded Al/steel dissimilar joints," J. Manuf. Process., vol. 49, no. November 2019, pp. 18$25,2020$.

[12] M. Yilmaz, M. Çöl, and M. Acet, "Interface properties of aluminum/steel friction-welded components," Mater. Charact., vol. 49, no. 5, pp. 421-429, 2002.

[13] W.-Y. Li, M. Yu, J. Li, G. Zhang, and S. Wang, "Characterizations of 21-4N to 4Cr9Si2 stainless steel dissimilar joint bonded by electric-resistance-heat-aided friction welding," Mater. Des., vol. 30, no. 10, pp. 4230-4235, 2009.

[14] S. L. Campanelli, G. Casalino, C. Casavola, and V. Moramarco, "Analysis and comparison of friction stir welding and laser assisted friction stir welding of aluminum alloy," Materials (Basel)., vol. 6, no. 12, pp. 5923-5941, 2013.

[15] M. Jabbari, "Effect of the Preheating Temperature on Process Time in Friction Stir Welding of Al 6061-T6," J. Eng., vol. 2013, 2013.

[16] M. Kutsuna, N. Yamagami, M. J. Rathod, and H. Y. A. Ammar, "Laser roll welding for joining of low-carbon steels to aluminium alloys," Weld. Int., vol. 20, no. 6, pp. 446-456, 2006.

[17] J. L. Mullo, J. Ramos-Grez, and G. O. Barrionuevo, "Effect of Laser Heat Treatment on the Mechanical Performance and Microstructural Evolution of AISI 1045 Steel-2017-T4 Aluminum Alloy Joints during Rotary Friction Welding," J. Mater. Eng. Perform., 2021.

[18] S. M. Chelly and C. Denis, "Introducing Machine Learning," Med. Sci. Sports Exerc., vol. 33, no. 2, pp. 326-333, 2001.

[19] I. Goodfellow, Y. Bengio, and A. Courville, Deep Learning Adaptive Computation and Machine Learning, vol. 1. 2016. 
[20] H. K. Gianey and R. Choudhary, "Comprehensive Review On Supervised Machine Learning Algorithms," Proc. - 2017 Int. Conf. Mach. Learn. Data Sci. MLDS 2017, vol. 2018-Janua, pp. 38$43,2018$.

[21] S. Sun, Z. Cao, H. Zhu, and J. Zhao, "A Survey of Optimization Methods From a Machine Learning Perspective," IEEE Trans. Cybern., pp. 1-14, 2019.

[22] N. Duffy and D. Helmbold, "Boosting Methods for Regression," Theor. Comput. Sci., vol. 284, no. 1, pp. 67-108, 2002.

[23] A. Prieditis and S. Sapp, "Lazy overfitting control," Lect. Notes Comput. Sci. (including Subser. Lect. Notes Artif. Intell. Lect. Notes Bioinformatics), vol. 7988 LNAI, pp. 481-491, 2013.

[24] A. Singh, N. Thakur, and A. Sharma, "A review of supervised machine learning algorithms," Proc. 10th INDIACom; 2016 3rd Int. Conf. Comput. Sustain. Glob. Dev. INDIACom 2016, pp. 13101315, 2016.

[25] O. Sagi and L. Rokach, "Ensemble learning: A survey," Wiley Interdiscip. Rev. Data Min. Knowl. Discov., vol. 8, no. 4, pp. 1-18, 2018.

[26] Z.-H. Zhou, Ensemble Methods Foundations and Algorithms. 2014.

[27] B. Eren, M. A. Guvenc, and S. Mistikoglu, "Artificial Intelligence Applications for Friction Stir Welding: A Review," Met. Mater. Int., vol. 27, no. 2, pp. 193-219, 2020.

[28] R. Hartl, F. Vieltorf, M. Benker, and M. F. Zaeh, "Predicting the ultimate tensile strength of friction stirwelds using gaussian process regression," J. Manuf. Mater. Process., vol. 4, no. 3, 2020.

[29] Y. Zhang and X. Xu, "Predicting the material removal rate during electrical discharge diamond grinding using the Gaussian process regression: a comparison with the artificial neural network and response surface methodology," Int. J. Adv. Manuf. Technol., pp. 1527-1533, 2021.

[30] R. Winiczenko, "Effect of friction welding parameters on the tensile strength and microstructural properties of dissimilar AISI 1020-ASTM A536 joints," Int. J. Adv. Manuf. Technol., vol. 84, no. 5-8, pp. 941-955, 2016.

[31] Y. Liu, H. Zhao, Y. Peng, and X. Ma, "Microstructure characterization and mechanical properties of the continuous-drive axial friction welded aluminum/stainless steel joint," Int. J. Adv. Manuf. Technol., vol. 104, no. 9-12, pp. 4399-4408, 2019.

[32] E. Taban, J. E. Gould, and J. C. Lippold, "Dissimilar friction welding of 6061-T6 aluminum and AISI 1018 steel: Properties and microstructural characterization," Mater. Des., vol. 31, no. 5, pp. 2305-2311, May 2010.

[33] G. Barrionuevo, J. Ramos-Grez, M. Walczak, and C. Betancourt, "Comparative evaluation of supervised machine learning algorithms in the prediction of the relative density of 316L stainless steel fabricated by selective laser melting," Int. J. Adv. Manuf. Technol., 2021.

[34] J. Deng, Y. Xu, Z. Zuo, Z. Hou, and S. Chen, "Bead Geometry Prediction for Multi-layer and Multibead Wire and Arc Additive Manufacturing Based on XGBoost," pp. 125-135, 2019.

[35] F. Pedregosa et al., "Scikit-learn: Machine Learning in Python," J. Mach. Learn. Res., vol. 19, no. 1, pp. 29-33, 2011.

[36] L. Buitinck et al., "API design for machine learning software: experiences from the scikit-learn project," pp. 1-15, 2013.

[37] I. Baturynska and K. Martinsen, "Prediction of geometry deviations in additive manufactured parts: comparison of linear regression with machine learning algorithms," J. Intell. Manuf., 2020.

[38] E. Taban, J. E. Gould, and J. C. Lippold, "Dissimilar friction welding of 6061-T6 aluminum and AISI 1018 steel: Properties and microstructural characterization," Mater. Des., vol. 31, no. 5, pp. 2305-2311, 2010. 


\section{Figures}

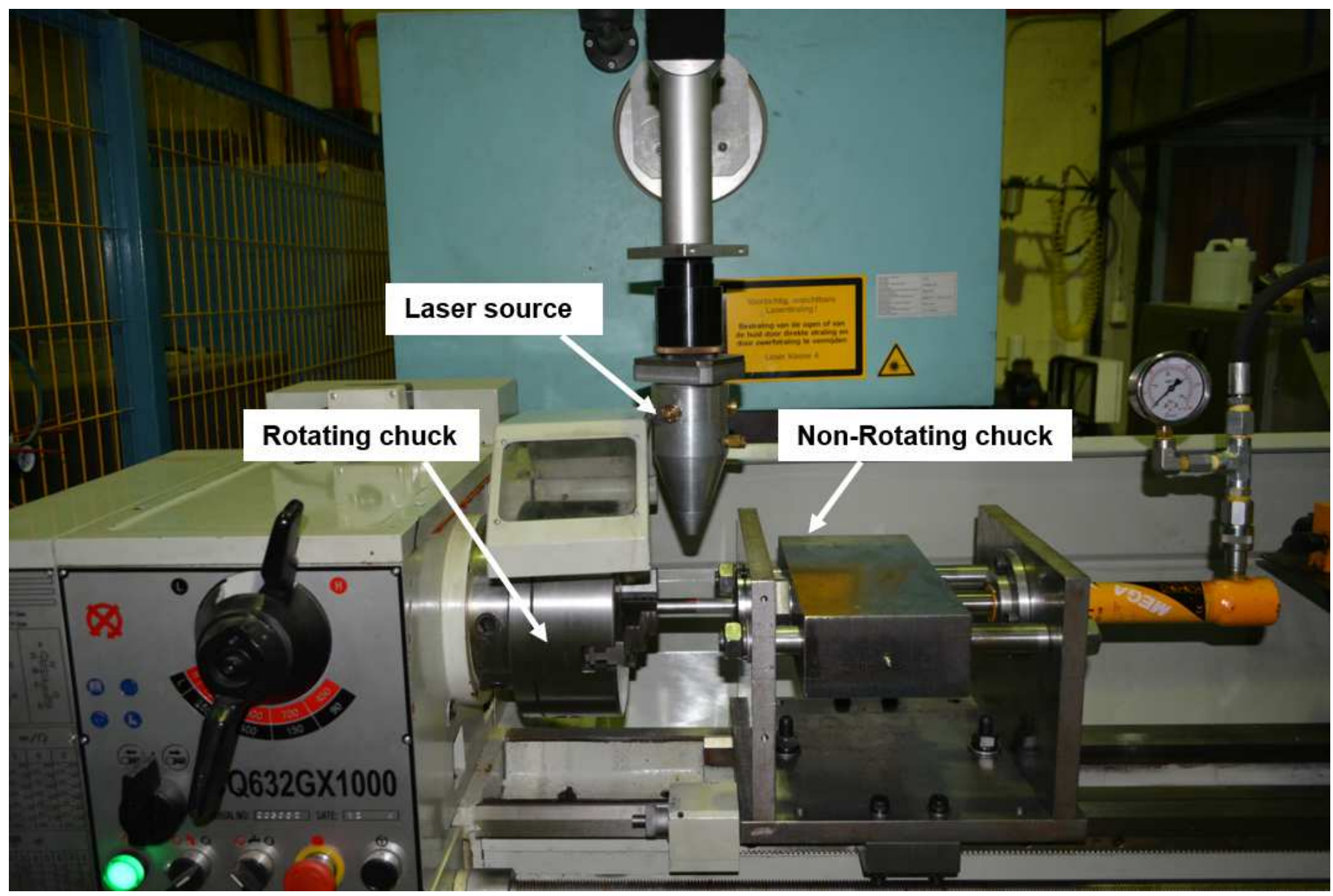

Figure 1

The experimental setup used for the laser-assisted rotary friction welding (LARFW) 


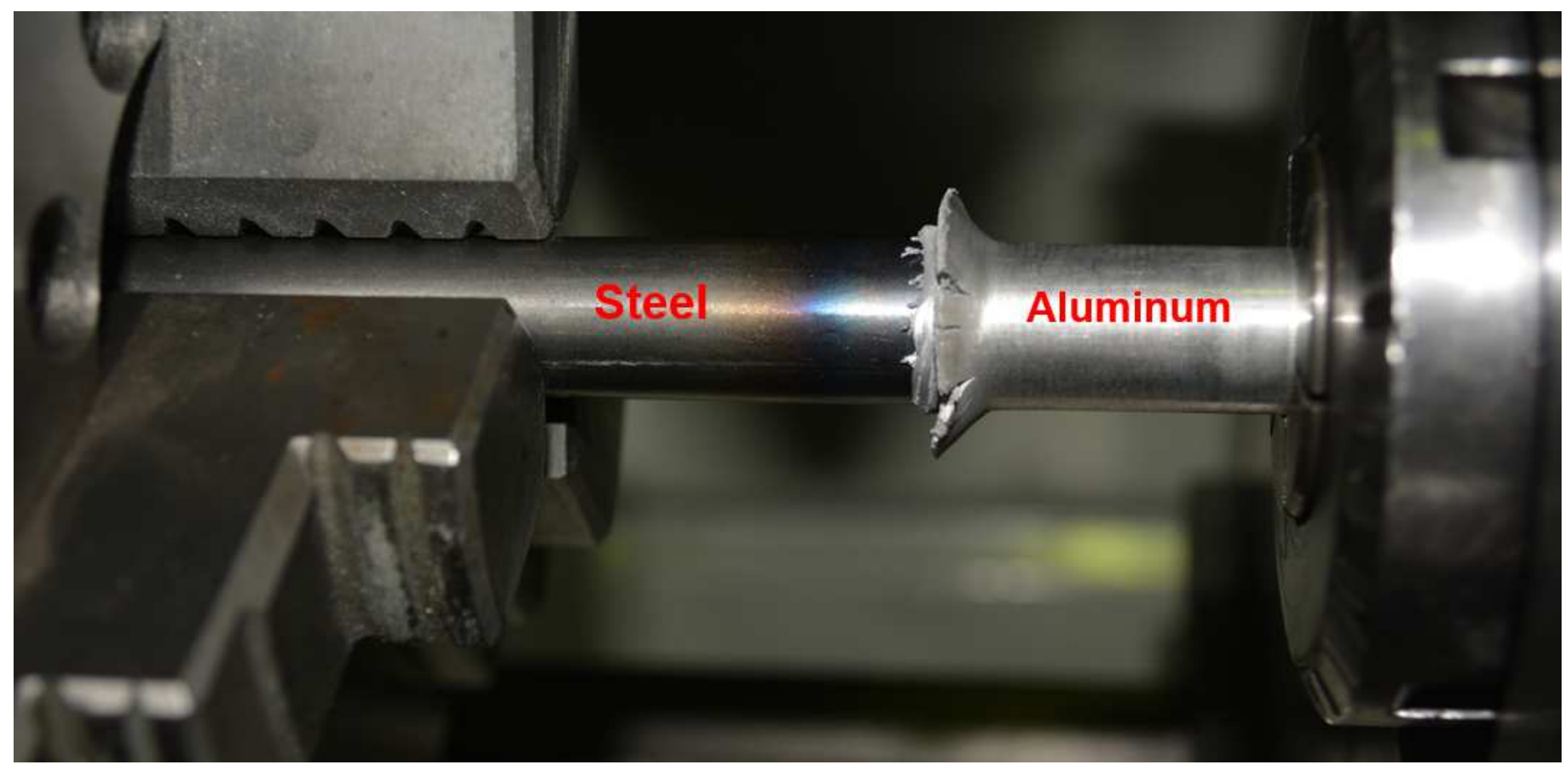

Figure 2

Flux formation around the aluminum alloy during rotary friction welding

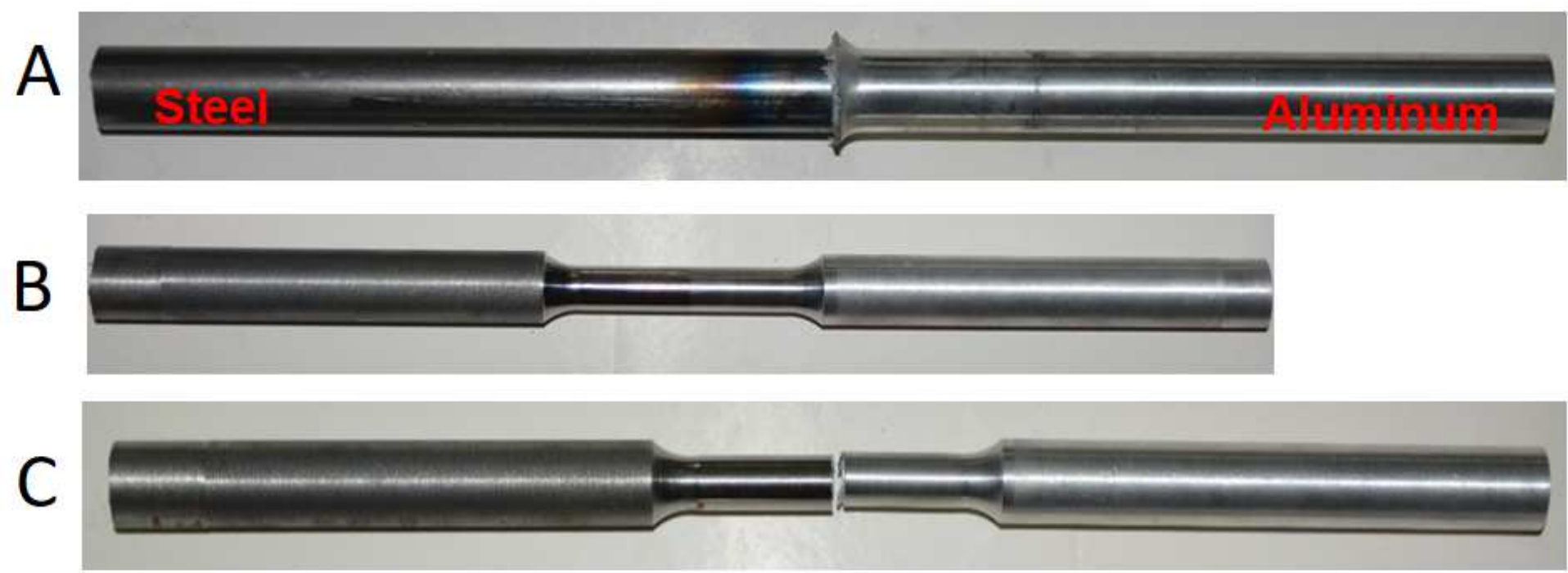

Figure 3

Welded joint specimen: a) as processed, b) after machined for tensile test, c) after tensile test up to fracture 


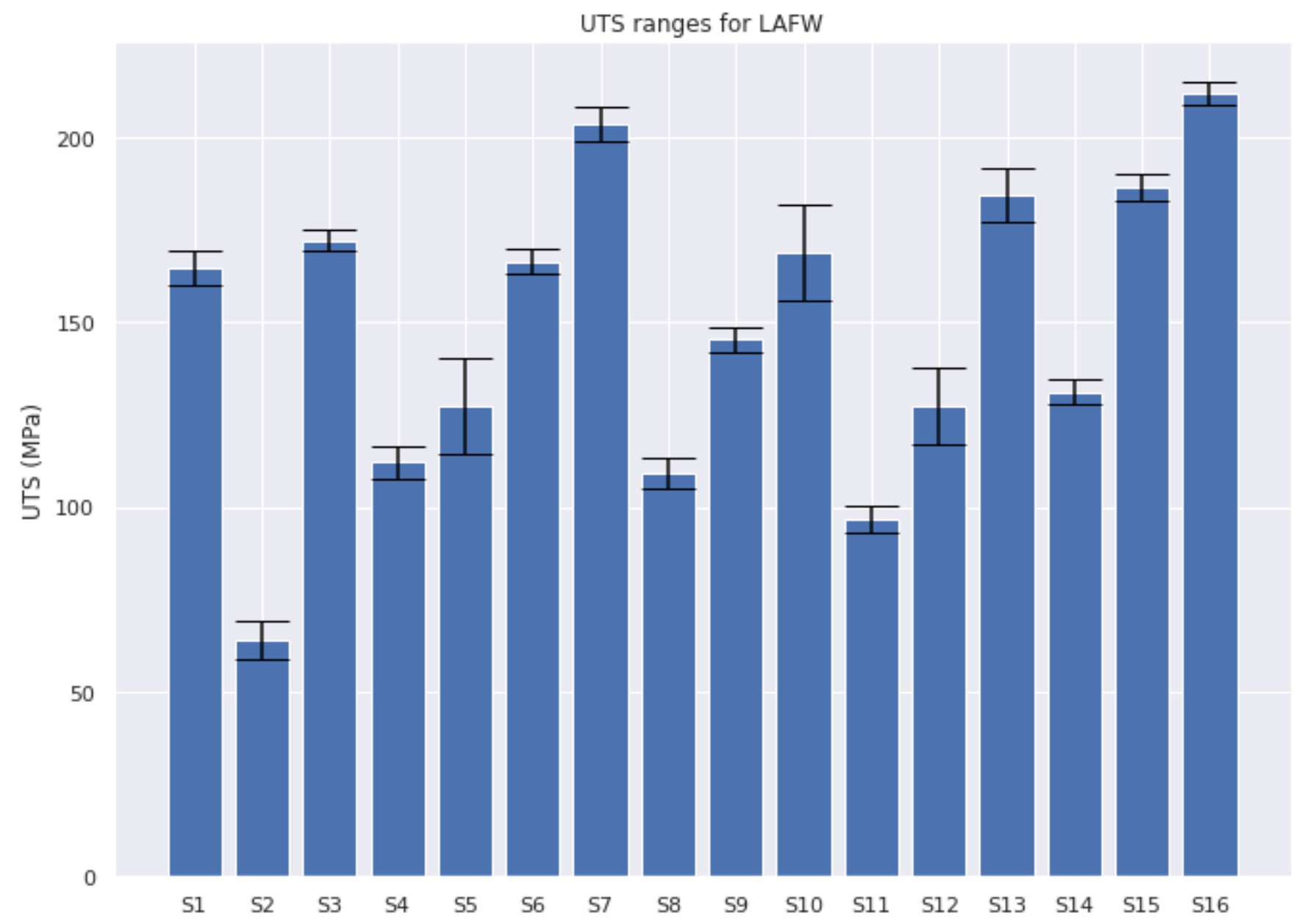

Figure 4

Boxplot of LARFW, UTS evaluation 


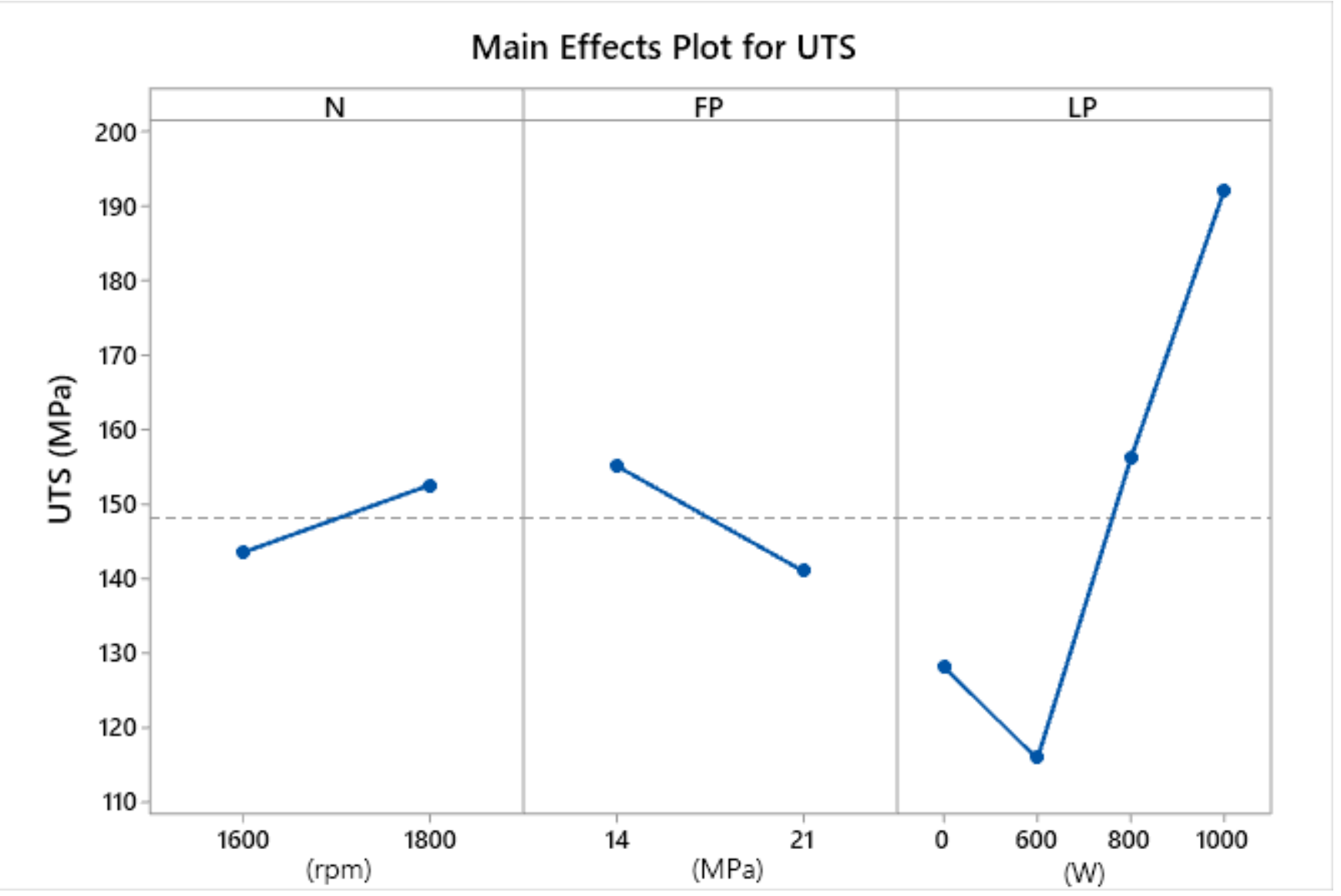

Figure 5

Main effects of experimental factors on the UTS 


\section{Interaction Plot for UTS}

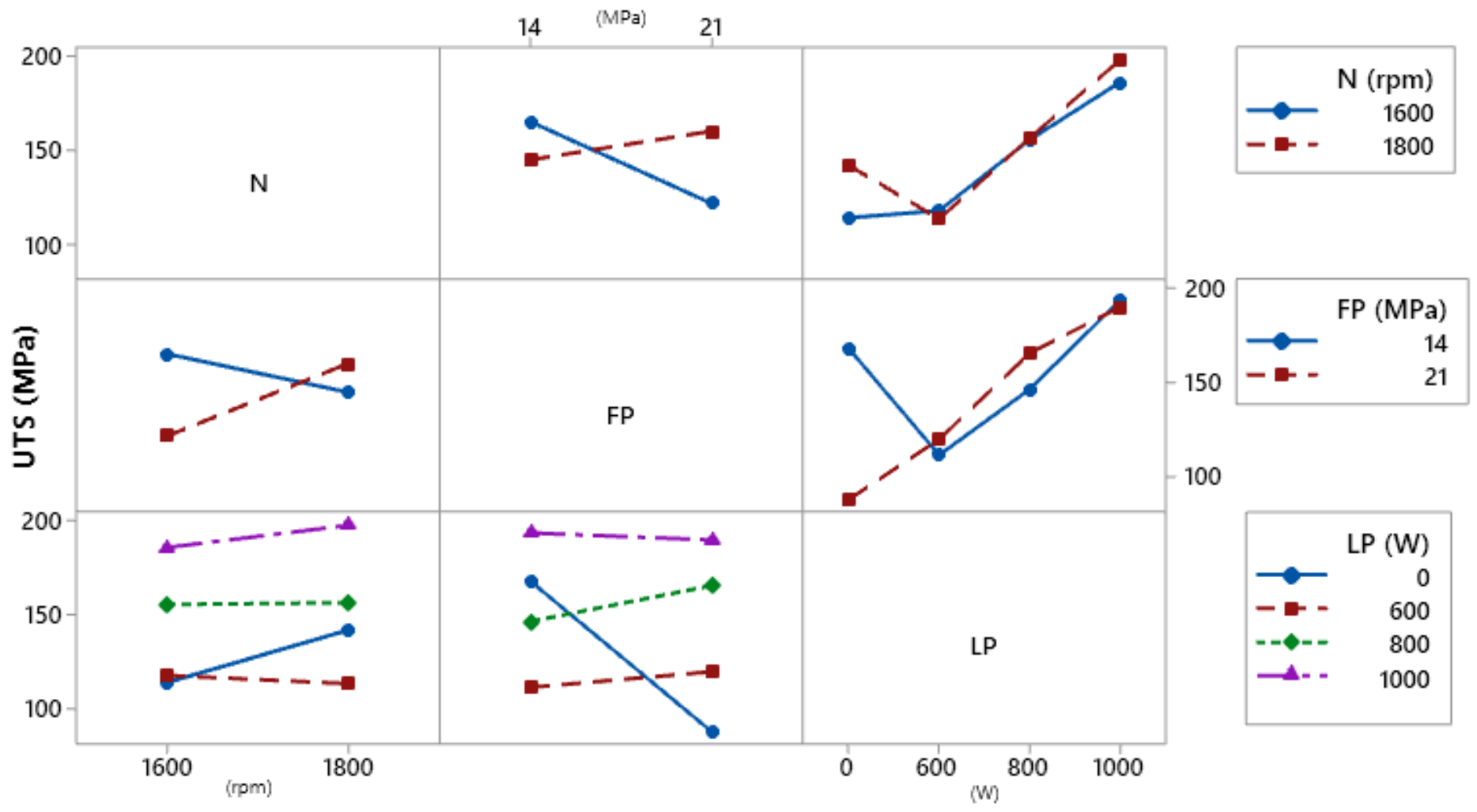

Figure 6

Interaction plot of factors on the overall UTS 


\section{Contour Plot of UTS vs FP; LP}

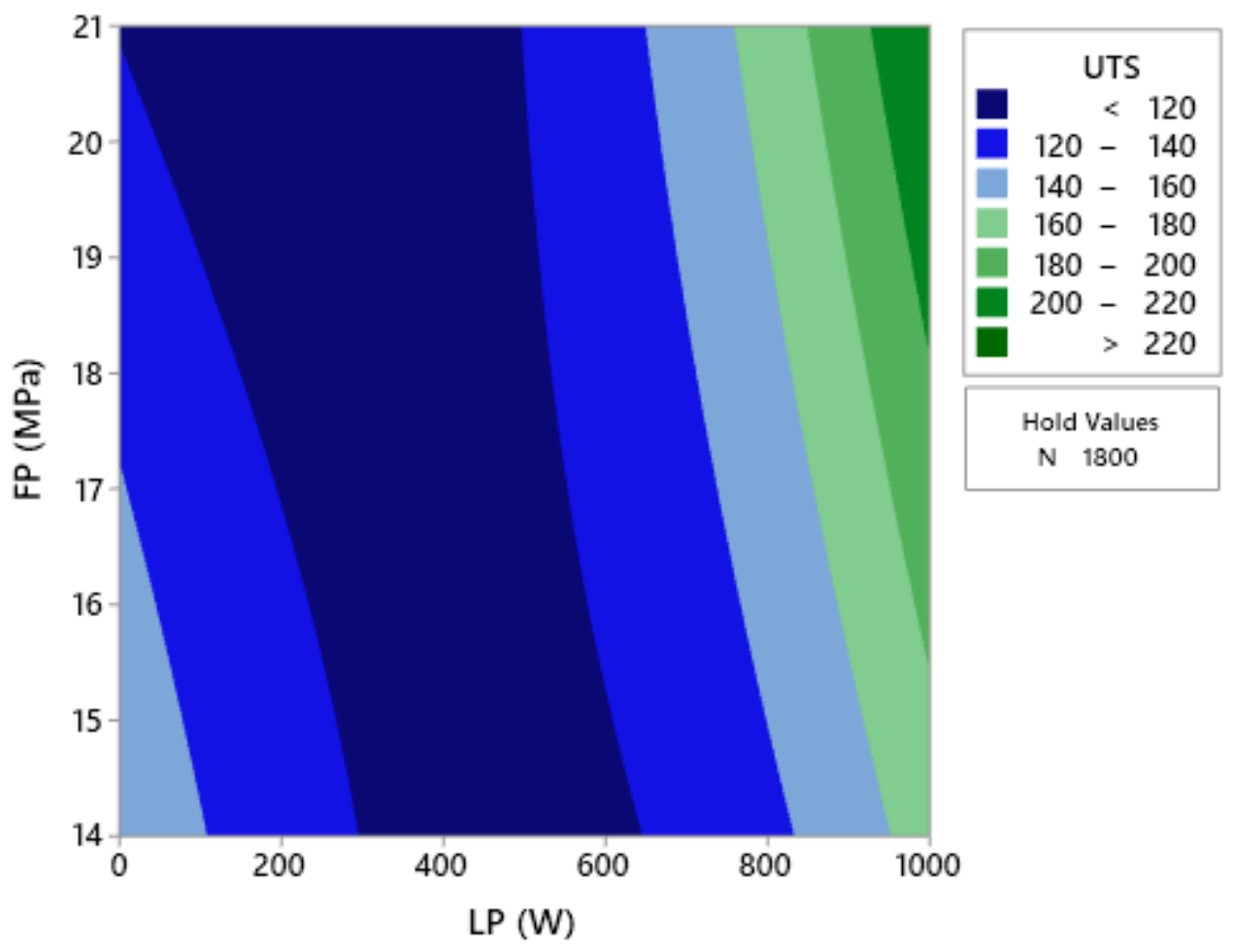

\section{Figure 7}

Contour plot of interaction between laser power and friction pressure

Contour Plot of UTS vs N; LP

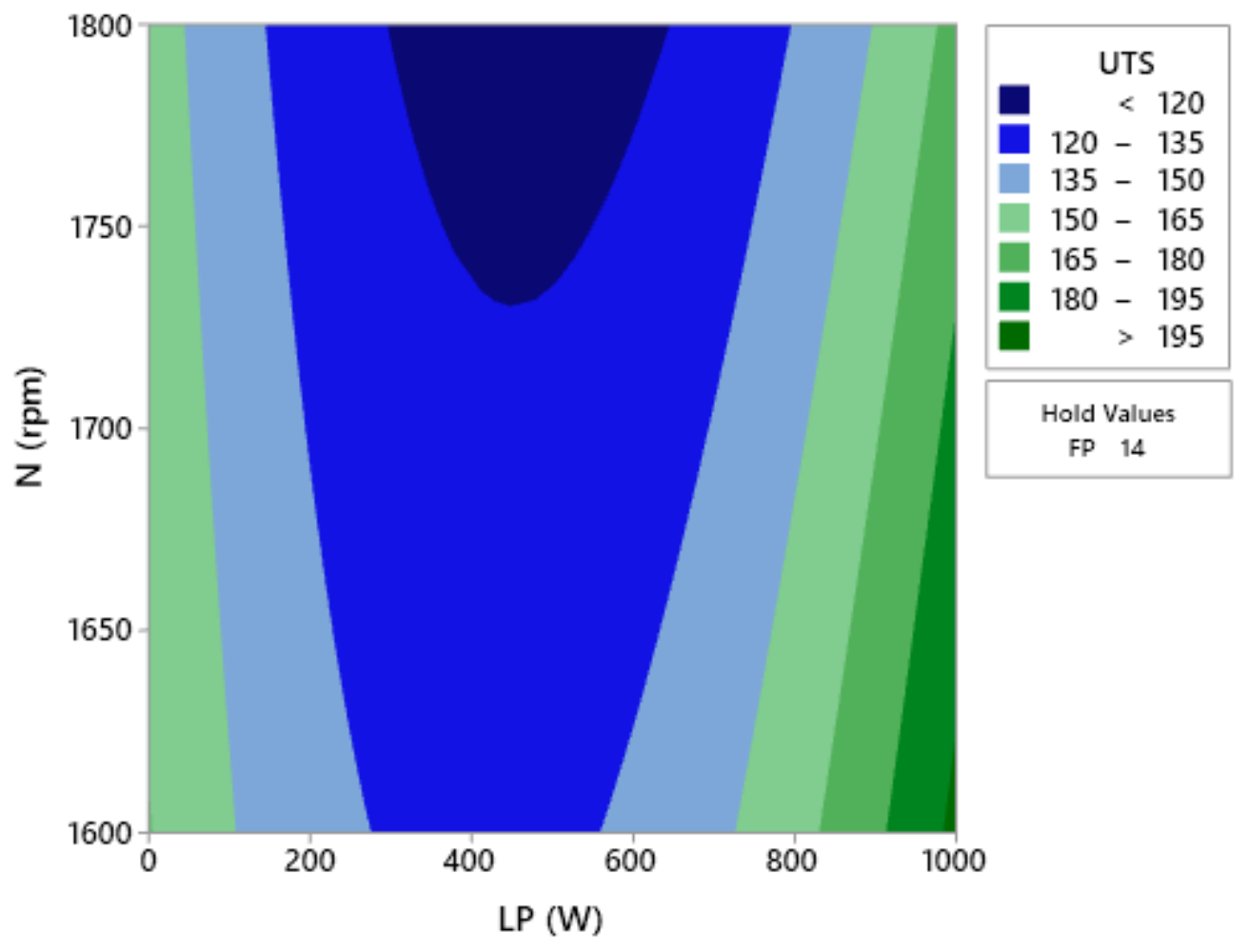


Figure 8

Contour plot of interaction between laser power and rotational speed

\section{Contour Plot of UTS vs N; FP}

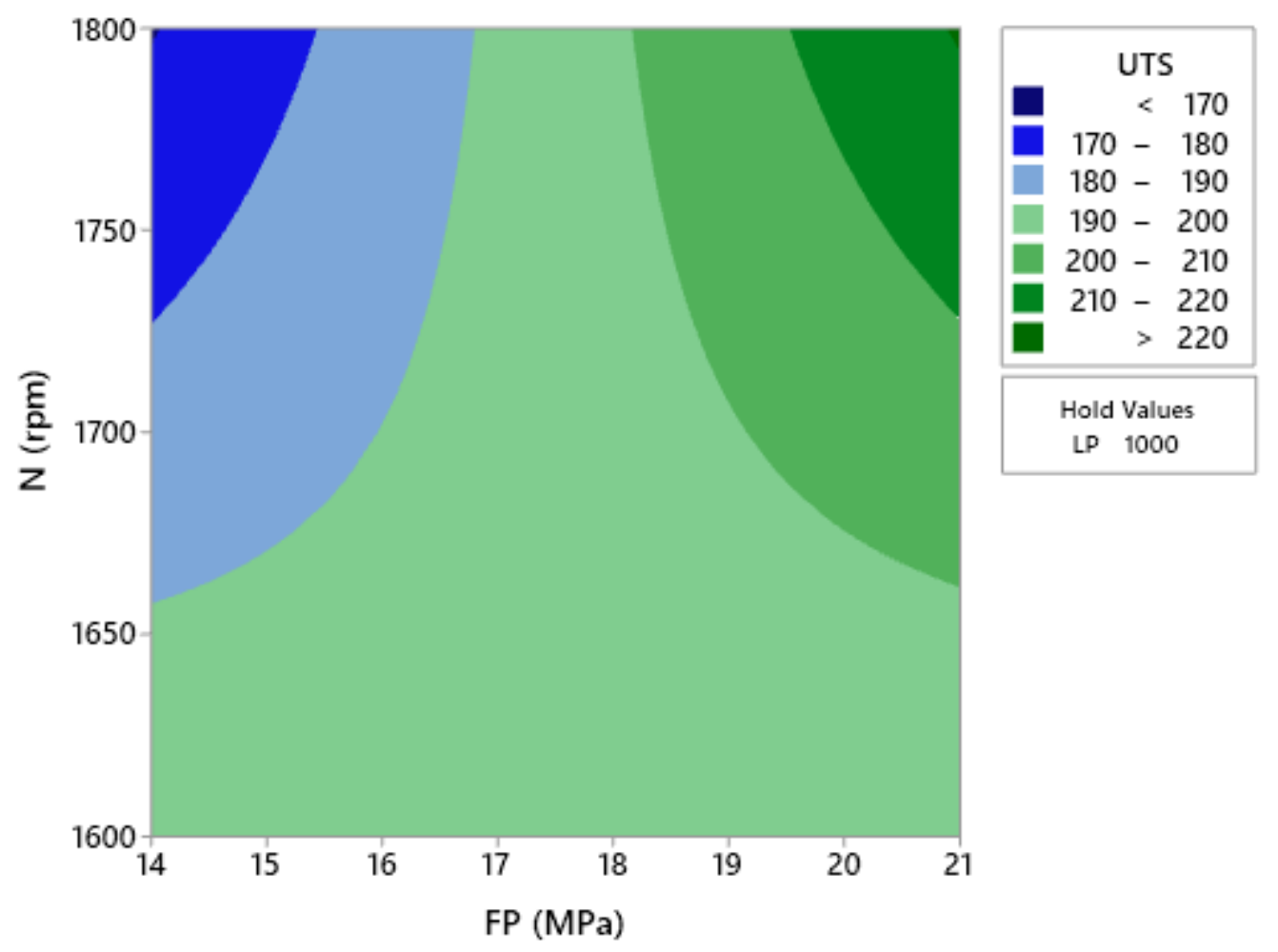

Figure 9

Contour plot of interaction between friction pressure and rotational speed 


\section{Pareto Chart of the Standardized Effects}

(response is UTS; $\alpha=0,05$ )

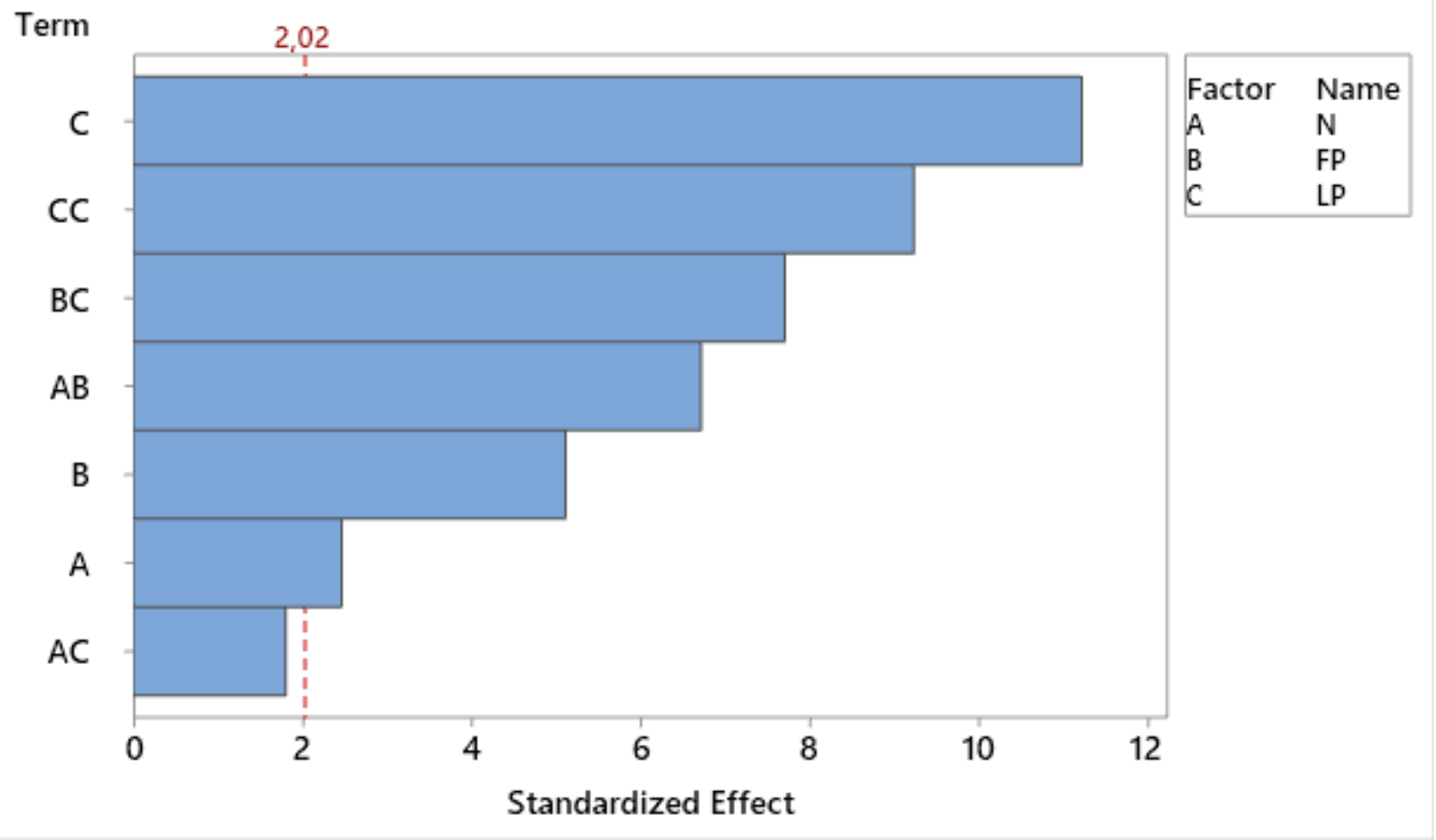

Figure 10

Pareto chart of the standardized effect

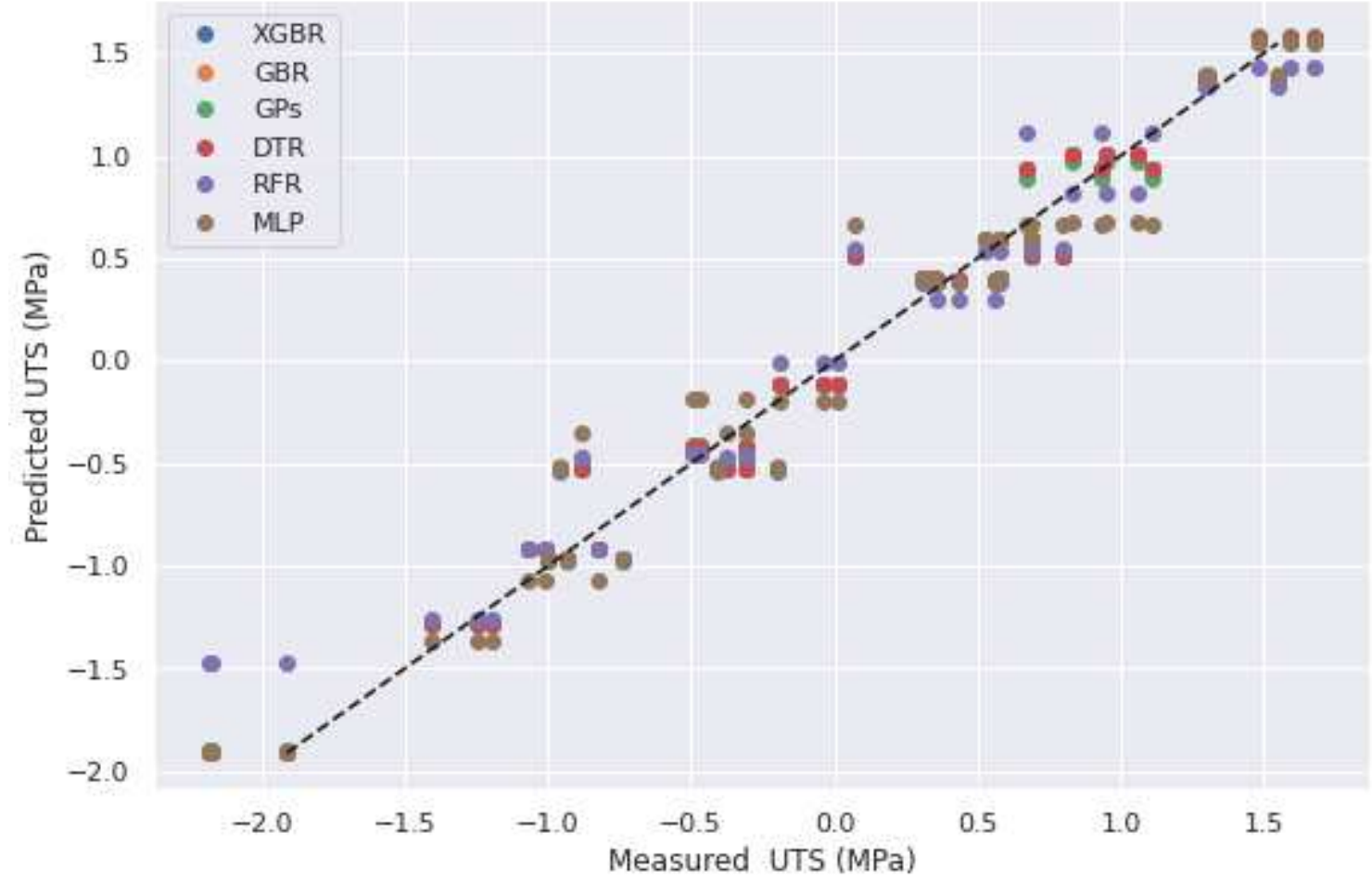

Figure 11

Scatter plot for comparing ML regressors accuracy in the UTS prediction 


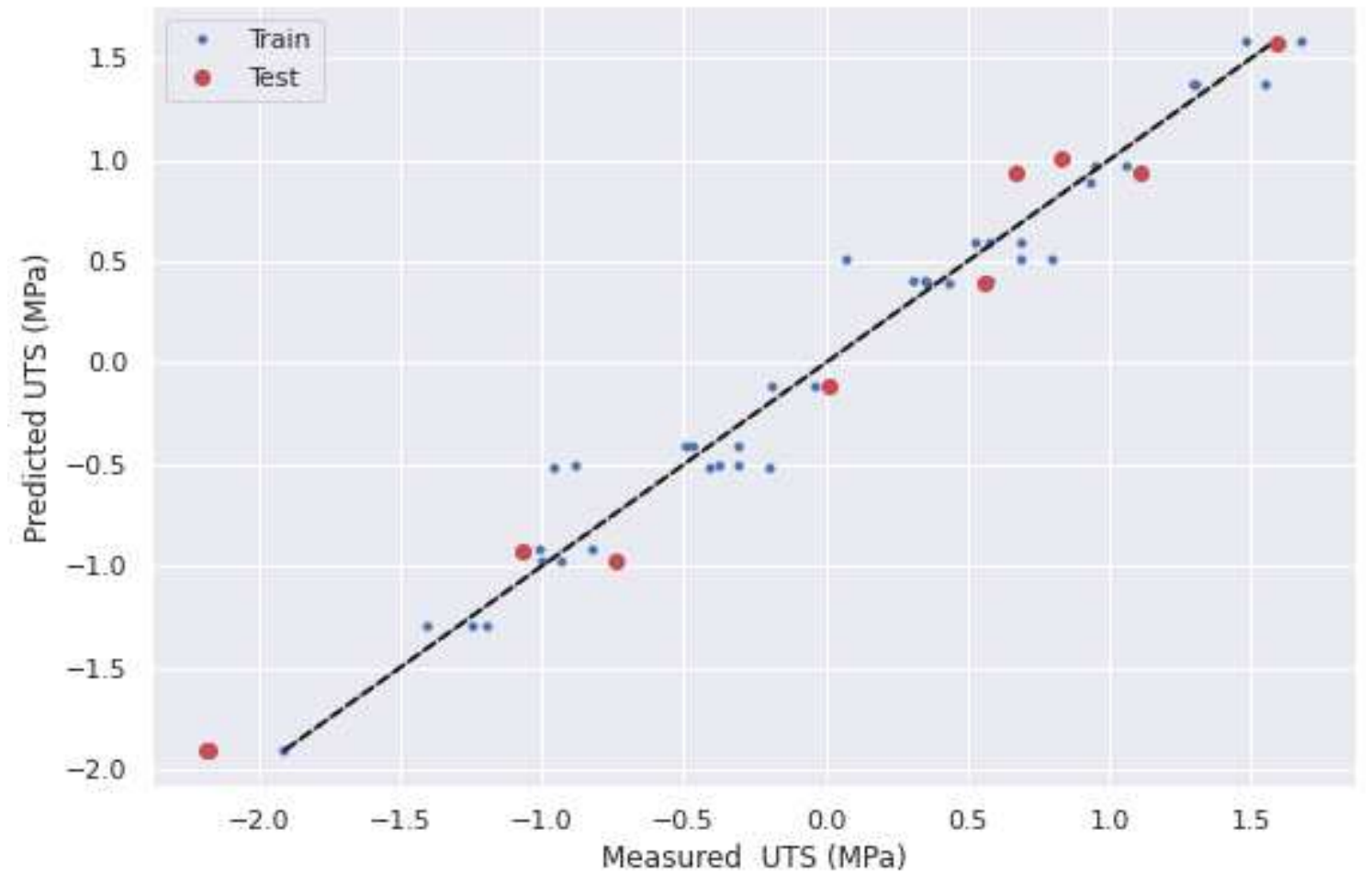

Figure 12

Scatter plot for accuracy evaluation of the GBR performance in the UTS prediction Feature: 0 , Score: 0.09419

Feature: 1, Score: 0.28351

Feature: 2, Score: 0.62230

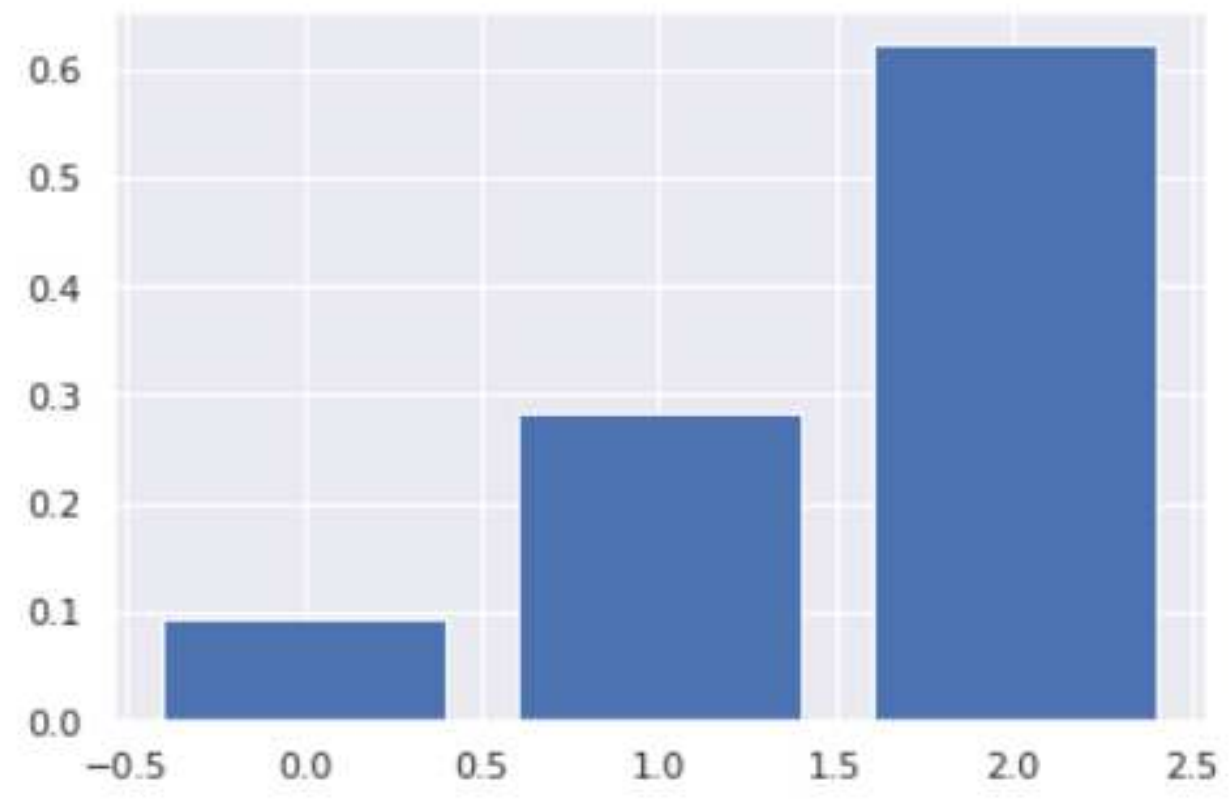

Figure 13

Feature importance analysis of the processing parameters in LARFW 